\title{
Meta-analytic evidence for a superordinate cognitive control network subserving diverse executive functions
}

\author{
Tara A. Niendam • Angela R. Laird • Kimberly L. Ray • \\ Y. Monica Dean - David C. Glahn - Cameron S. Carter
}

Published online: 27 January 2012

(C) Psychonomic Society, Inc. 2012

\begin{abstract}
Classic cognitive theory conceptualizes executive functions as involving multiple specific domains, including initiation, inhibition, working memory, flexibility, planning, and vigilance. Lesion and neuroimaging experiments over the past two decades have suggested that both common and unique processes contribute to executive functions during higher cognition. It has been suggested that a superordinate fronto-cingulo-parietal network supporting cognitive control may also underlie a range of distinct executive functions. To test this hypothesis in the largest sample to date, we used quantitative meta-analytic methods to analyze 193 functional neuroimaging studies of 2,832 healthy individuals, ages $18-60$, in which performance on executive function measures was contrasted with an active control condition. A common pattern of activation was observed in the prefrontal, dorsal anterior cingulate, and parietal cortices across executive function domains, supporting the idea that executive functions are supported by a superordinate cognitive control network.
\end{abstract}

\footnotetext{
T. A. Niendam $(\bowtie) \cdot$ Y. M. Dean $\cdot$ C. S. Carter Imaging Research Center, University of California, Davis, 4701 X Street, Suite E,

Sacramento, CA 95817, USA

e-mail: tniendam@ucdavis.edu

A. R. Laird · K. L. Ray

Research Imaging Institute,

University of Texas Health Science Center,

San Antonio, TX, USA

D. C. Glahn

Olin Neuropsychiatric Research Center, Institute of Living,

Yale University School of Medicine,

New Haven, CT, USA

D. C. Glahn

Department of Psychiatry, Yale University School of Medicine,

New Haven, CT, USA
}

However, domain-specific analyses showed some variation in the recruitment of anterior prefrontal cortex, anterior and midcingulate regions, and unique subcortical regions such as the basal ganglia and cerebellum. These results are consistent with the existence of a superordinate cognitive control network in the brain, involving dorsolateral prefrontal, anterior cingulate, and parietal cortices, that supports a broad range of executive functions.

Keywords Cognitive control $\cdot$ Prefrontal cortex $\cdot$ Executive function · Activation likelihood estimation $\cdot$ Meta-analysis

Early cognitive theories posited that cognitive functions are modular in nature and located within separable but interconnected parts of the brain (Luria, 1970; Shallice, 1988). Within this framework, executive functions have been described as a set of superordinate processes that guide thought and behavior and allow purposive action toward a goal (Miller, 2000). These functions are critical for normal day-to-day cognitive functioning and appear to be particularly susceptible to altered development, injury, and disease. From a traditional cognitive or neuropsychological perspective, executive functions have been thought to comprise a set of distinct cognitive domains that include vigilance, or sustained attention (Pennington \& Ozonoff, 1996; Smith \& Jonides, 1999); initiation of complex goal-directed behaviors (Lezak, 1995); inhibition of prepotent but incorrect responses (Luna, Padmanabhan, \& O'Hearn, 2010; Smith \& Jonides, 1999); flexibility to shift easily between goal states (Ravizza \& Carter, 2008); planning the necessary steps to achieve a goal (Smith \& Jonides, 1999); and working memory, the ability to hold information in mind and manipulate it to guide response selection (Goldman-Rakic, 1996). 
These theoretically distinct domains are supported by discrete neural systems (Luria, 1970; Shallice, 1988), which typically include elements of the prefrontal cortex (PFC). Early animal lesion studies provided evidence for PFC involvement in the coordination of complex behaviors, by serving as a temporary store for incoming information, making this information immediately available to guide response selection (Fuster, 1990; Goldman-Rakic, 1987; Jacobsen, 1936). Prefrontal damage in humans also impairs various executive functions, including planning (Owen, Downes, Sahakian, Polkey, \& Robbins, 1990; Shallice, 1982, 1988), flexibility (Milner, 1982), response inhibition (Leimkuhler \& Mesulam, 1985), and working memory (Milner, 1982).

Early neuroimaging and human lesion studies revealed that the frontal cortex is just one element in a network of spatially distinct regions associated with executive functions (Baddeley \& Wilson, 1988). For example, neuroimaging studies of a prototypical working memory task, the $n$-back paradigm, have consistently shown activated regions in the frontal and posterior parietal cortex and cerebellum (Owen, McMillan, Laird, \& Bullmore, 2005). Within this task, Broca's area and premotor cortex have been associated with subvocal rehearsal processes, while posterior parietal areas were associated with the storage of verbal information (Awh et al., 1996). On tasks that require flexibility, the ability to flexibly switch attention and behavioral responses between different rules is associated with activation of dorsolateral PFC (DLPFC), while switching attention responses between different perceptual features of a stimulus is associated with parietal activation (Ravizza \& Carter, 2008).

While traditional theories of executive functions have posited a set of distinct domains supported by at least partially unique brain regions, increasing numbers of functional neuroimaging studies examining diverse executive functions have suggested that these tasks may engage very similar brain networks (e.g., Duncan \& Owen, 2000). Recent views of the PFC highlight its role in higher cognitive functions by supporting coordinated activation of multiple brain areas within the "cognitive control network," including the DLPFC, medial frontal cortex (including the anterior cingulate cortex $[\mathrm{ACC}])$, parietal cortex, motor areas, and cerebellum (Bellebaum \& Daum, 2007; Braver, Cohen, \& Barch, 2002; D'Esposito, 2007; Fuster, 2002). Furthermore, analyses of functional connectivity in healthy adults revealed that coordinated temporal activation across the network of prefrontal and posterior brain regions is associated with better performance on cognitive control tasks (Fornito, Yoon, Zalesky, Bullmore, \& Carter, 2011; Yoon et al., 2008). Miller and Cohen proposed that the PFC supports "cognitive control" by actively maintaining "rules" online in order to evaluate incoming information, as well as internal states to guide response selection toward a current goal (Miller, 2000; Miller \& Cohen, 2001). According to this view, cognitive control mechanisms support the range of executive functions, including working memory, selective attention, stimulus-response mapping, and performance monitoring (Carter et al., 1998; Cohen, Dunbar, \& McClelland, 1990; Miyake \& Shah, 1999; Shallice, 1988), and are not restricted to a particular cognitive domain (Banich, 1997; Smith \& Jonides, 1999).

The diverse array of executive functions has limited our ability to directly test the unitary or modular nature of the underlying brain systems within a single set of experiments. Capitalizing on the unique power of activation likelihood estimation (ALE) meta-analytic tools, this study is the first to synthesize almost 200 published reports, testing the hypothesis that traditional executive functions are supported by a common PFC-related cognitive control network. The ALE meta-analytic approach models three-dimensional coordinates (from reported activations in standard space) as the center of a three-dimensional Gaussian distribution (Laird, Fox, et al., 2005). By combining published data from a wide variety of studies, the ALE method provides the unique opportunity to examine this question in the largest sample of control subjects published to date. Activation likelihood estimation has been has been used to address similar research questions in both healthy and patient samples (Binder, Desai, Graves, \& Conant, 2009; Caspers, Zilles, Laird, \& Eickhoff, 2010; Chouinard \& Goodale, 2010; Dickstein, Bannon, Castellanos, \& Milham, 2006; Fusar-Poli et al., 2009; Glahn et al., 2005; Goghari, 2010; Mana, Paillere Martinot, \& Martinot, 2010; Minzenberg, Laird, Thelen, Carter, \& Glahn, 2009; Molenberghs, Cunnington, \& Mattingley, 2009; Owen et al., 2005; Ragland et al., 2009; Richlan, Kronbichler, \& Wimmer, 2009; Samson, Mottron, Soulieres, \& Zeffiro, 2011; Schwindt \& Black, 2009; Spaniol et al., 2009; Turkeltaub \& Coslett, 2010; Yu et al., 2010). We hypothesized that healthy adults would show a common pattern of activation across prefrontal (DLPFC, ACC) and parietal regions when performing executive function tasks across multiple domains (see Table 1). Furthermore, we hypothesized that additional areas of domain-specific activation may be observed, but these would occur in addition to the common pattern of activation within the cognitive control network.

\section{Method}

Study selection

A search of the BrainMap database (Fox \& Lancaster, 2002; Laird, Fox, et al., 2005) was performed to identify all English-language, peer-reviewed studies that investigated executive function tasks in multiple healthy individuals, 
Table 1 Definitions of the cognitive domains examined within this study, tasks included within each of the domains, the total numbers of available studies examined, and the total numbers of studies and subjects included in the present analysis, by domain and task

\begin{tabular}{|c|c|c|c|c|c|}
\hline Cognitive Domain & Definition & $\begin{array}{l}\text { Task Included } \\
\text { in Domain }\end{array}$ & $\begin{array}{l}\text { Number of } \\
\text { Available } \\
\text { Studies }\end{array}$ & $\begin{array}{l}\text { Number of Studies } \\
\text { Included in Current } \\
\text { Analysis }\end{array}$ & $\begin{array}{l}\text { Total Numbe } \\
\text { of Subjects } \\
\text { Included }\end{array}$ \\
\hline \multirow[t]{2}{*}{ Flexibility $^{1,2}$} & \multirow[t]{2}{*}{ Switch from one task OR rule to another } & Task switching & 26 & 12 & 201 \\
\hline & & $\begin{array}{l}\text { Wisconsin Card } \\
\text { Sorting Test }\end{array}$ & 16 & 9 & 129 \\
\hline \multirow[t]{5}{*}{ Inhibition $^{1,3}$} & \multirow{5}{*}{$\begin{array}{l}\text { Inhibit prepotent response in order to } \\
\text { make correct, but less common, response }\end{array}$} & Antisaccades & 13 & 11 & 149 \\
\hline & & Flanker task & 10 & 9 & 108 \\
\hline & & Go/no-go task & 40 & 23 & 417 \\
\hline & & Simon task & 12 & 10 & 192 \\
\hline & & Stroop task & 55 & 26 & 346 \\
\hline \multirow[t]{5}{*}{ Working memory ${ }^{4}$} & \multirow{5}{*}{$\begin{array}{l}\text { Maintain information/context/ temporal } \\
\text { or spatial relationships online and } \\
\text { manipulate or use that information to } \\
\text { guide response selection }\end{array}$} & $\begin{array}{l}\text { Complex calculation/ } \\
\text { PASAT }\end{array}$ & 39 & 11 & 152 \\
\hline & & Delayed match to sample & 24 & 12 & 150 \\
\hline & & $N$-back/AXCPT & 73 & 37 & 502 \\
\hline & & $\begin{array}{l}\text { Spatial span/sequence } \\
\text { recall }\end{array}$ & 20 & 3 & 24 \\
\hline & & Sternberg task & 21 & 15 & 232 \\
\hline Initiation $^{5}$ & Initiate sequence of complex behaviors & Word generation & 85 & 9 & 115 \\
\hline Planning ${ }^{1}$ & $\begin{array}{l}\text { Identify and organize steps and elements } \\
\text { needed to carry out an intention or } \\
\text { achieve a goal }\end{array}$ & Tower Maze test & 13 & 4 & 51 \\
\hline \multirow[t]{2}{*}{ Vigilance $^{1,6}$} & $\begin{array}{l}\text { Maintaining set in the face of } \\
\text { interference }\end{array}$ & Oddball discrimination & 10 & 2 & 64 \\
\hline & & TOTAL $=$ & 457 & 193 & 2,832 \\
\hline
\end{tabular}

${ }^{1}$ Smith and Jonides (1999). ${ }^{2}$ Ravizza and Carter (2008). ${ }^{3}$ Luna et al. (2010). ${ }^{4}$ Goldman-Rakic (1996). ${ }^{5}$ Lezak (1995). ${ }^{6}$ Pennington and Ozonoff (1996).

ages 18-60 years, using functional magnetic resonance imaging (fMRI) or positron emission tomography (PET). Executive functions were defined as processes that are required in order to regulate or guide other cognitive processes in order to support goal-directed behavior (Minzenberg et al., 2009). For the purpose of this investigation, we examined studies that used task paradigms that are typically considered measures of executive function or cognitive control. As outlined in Table 1, these included measures of vigilance, inhibition, flexibility, planning, working memory, and initiation. Within each study, we included data from healthy individuals on specific contrasts that examined withingroup whole-brain activation in response to a task of interest that was compared to an active control task, rather than to rest or fixation. Studies were excluded if the subject pool overlapped with other published studies on smaller subsets of the same sample or included subjects outside of the age range (18-60 years), if the task of interest did not require an appropriate behavioral response (e.g., a buttonpress), or if contrasts with the available coordinate data did not examine a specific executive function or rather examined differences between patients and controls. Table 1 provides the numbers of studies that were available and that met the criteria for inclusion within each domain. The BrainMap database archives the peak coordinates of activations as well as their corresponding metadata, such as the number and diagnosis of the subjects, the analysis technique, the paradigm, and the cognitive domain. Coordinates originally published in MNI space were converted to Talairach space using the Lancaster (icbm2tal) transformation (Laird et al., 2010; Lancaster et al., 2007). Further filtering and meta-analysis of the experiments was carried out using BrainMap's software applications (Laird et al., 2009), as described below.

\section{Activation likelihood estimation}

We performed a series of coordinate-based meta-analyses of executive functioning using the ALE method (Laird, McMillan, et al., 2005; Turkeltaub, Eden, Jones, \& Zeffiro, 2002), in which the voxel-wise correspondence of neuroimaging results is assessed across a large number of studies. The ALE algorithm aims to identify areas showing a higher convergence of findings across experiments than would be expected under a spatially random spatial association. The identified literature coordinates were modeled with a threedimensional Gaussian probability distribution reflecting the spatial uncertainty of each focus on the basis of an estimation of the intersubject and interlaboratory variability 
typically observed in neuroimaging experiments. This algorithm limits the meta-analysis to an anatomically constrained space specified by a gray-matter mask and includes a method that calculates the above-chance clustering between experiments (i.e., random-effects analysis), rather than between foci (i.e., fixed-effects analysis), and it also accounts for differences in sample sizes across the included studies (Eickhoff et al., 2009). The probabilities of all foci reported in a given experiment were combined, resulting in a modeled activation map for each experiment, and the union of these probabilities was computed in order to derive voxel-wise ALE values that described the convergence of results across the whole brain. To determine which ALE values were statistically significant, ALE scores were compared with an empirical null distribution reflecting a random spatial association between experiments, thereby estimating convergence between studies rather than the clustering of foci within a particular study.

ALE was performed in Talairach space using GingerALE 2.0 (http://brainmap.org/ale/index.html) to analyze the global set of activation foci for concordance, as well as subsets of foci that corresponded to the cognitive components of interest within executive function. From the set of included studies (Table 2), the results for a global set of within-group activations across all six domains were meta-analyzed to address the primary hypothesis. To examine the foci of greatest concordance across studies, we also performed a conjunction analysis across the three domains in which the data from more than nine studies were available (flexibility, inhibition, and working memory). To examine potential domain-specific patterns of activation, we completed withingroup meta-analyses for the domains in which data from more than nine studies were available. The resultant ALE maps were thresholded at a false-discovery rate (FDR)-corrected threshold of $p<.05$. Images were viewed in Mango ("multiimage analysis GUI"), developed at the Research Imaging Institute in San Antonio (http://ric.uthscsa.edu/mango/).

\section{Results}

Global analysis across all domains

Across all domains (shown in red in Fig. 1; see also Table 3a), large clusters of significant activation were observed within lateral and medial PFC bilaterally, encompassing superior, middle, and inferior frontal gyri including the DLPFC (Brodmann areas [BAs] 9, 46), as well as the ACC (BA 32) on the medial wall. In addition to prefrontal activation, the overall contrast revealed large parietal clusters, including the inferior (BA 40) and superior (BA 7) parietal lobe. This combined frontal-parietal activation is consistent with previous findings related to the cognitive control circuit
(Botvinick, Braver, Barch, Carter, \& Cohen, 2001; Carter, Botvinick, \& Cohen, 1999; Cohen, Botvinick, \& Carter, 2000; Yarkoni et al., 2005). Additional activation in frontal regions included the premotor cortex (BA 6), frontopolar cortex (BA 10), and orbitofrontal cortex (BA 11). Activation was also observed in occipital (BA 19) and temporal (BAs $13,22,37)$ regions, which are consistent with processing of the verbal and auditory stimuli, respectively, that are presented as part of the included tasks. Finally, significant activation was found in subcortical structures, including the thalamus, caudate, and putamen, as well as areas of the cerebellum, including the posterior declive and anterior culmen. These findings are consistent with the hypothesis that executive functions are supported by a common set of cortical and subcortical regions within the cognitive control network.

Results of the conjunction analysis (shown in green in Fig. 1; see also Table 3b) across the three domains for which the data from more than nine studies were available (flexibility, inhibition, and working memory) revealed similar patterns of common activation in cognitive-control-related frontal and parietal regions, including the DLPFC (BAs 9, 46), anterior cingulate (BA 32), inferior (BAs 39, 40) and superior (BA 7) parietal lobe, and precuneus (BA 19). The results of these analyses can be examined through an interactive viewer at http://carterlab.ucdavis.edu/research/ale_analysis.php.

\section{Domain-specific within-group analysis}

Flexibility For tasks that examined flexibility, similar patterns of activation were observed in frontal and parietal regions supporting the cognitive control network (see Fig. 2 and Table 4), including the DLPFC (BAs 9, 46), cingulate (BAs 32, 24), as well as superior (BA 7) and inferior (BA 40) parietal lobe. Activation was also observed in additional prefrontal (BAs 6, 10, 11), occipital (BA 19), and temporal (BAs 13,37) regions.

Inhibition As is shown in Fig. 2 (see Table 5), tasks that require inhibition were associated with activation in frontal and parietal cognitive-control-related regions, including DLPFC (BAs 9, 46), ACC (BA 32), and superior (BA 7) and inferior (BA 40) parietal lobe. Such tasks also elicited activation in other prefrontal (BAs 6, 10), occipital (BA 19), and temporal (BA 13) regions. Activation of subcortical regions included the caudate, thalamus, putamen, and cerebellar declive.

Working memory Working memory tasks elicited the common pattern of frontal-parietal activation associated with the cognitive control network (see Fig. 2 and Table 6), including the DLPFC (BAs 9, 46), cingulate (BAs 32, 24), and parietal lobe (BAs 7, 40). A consistent pattern of 


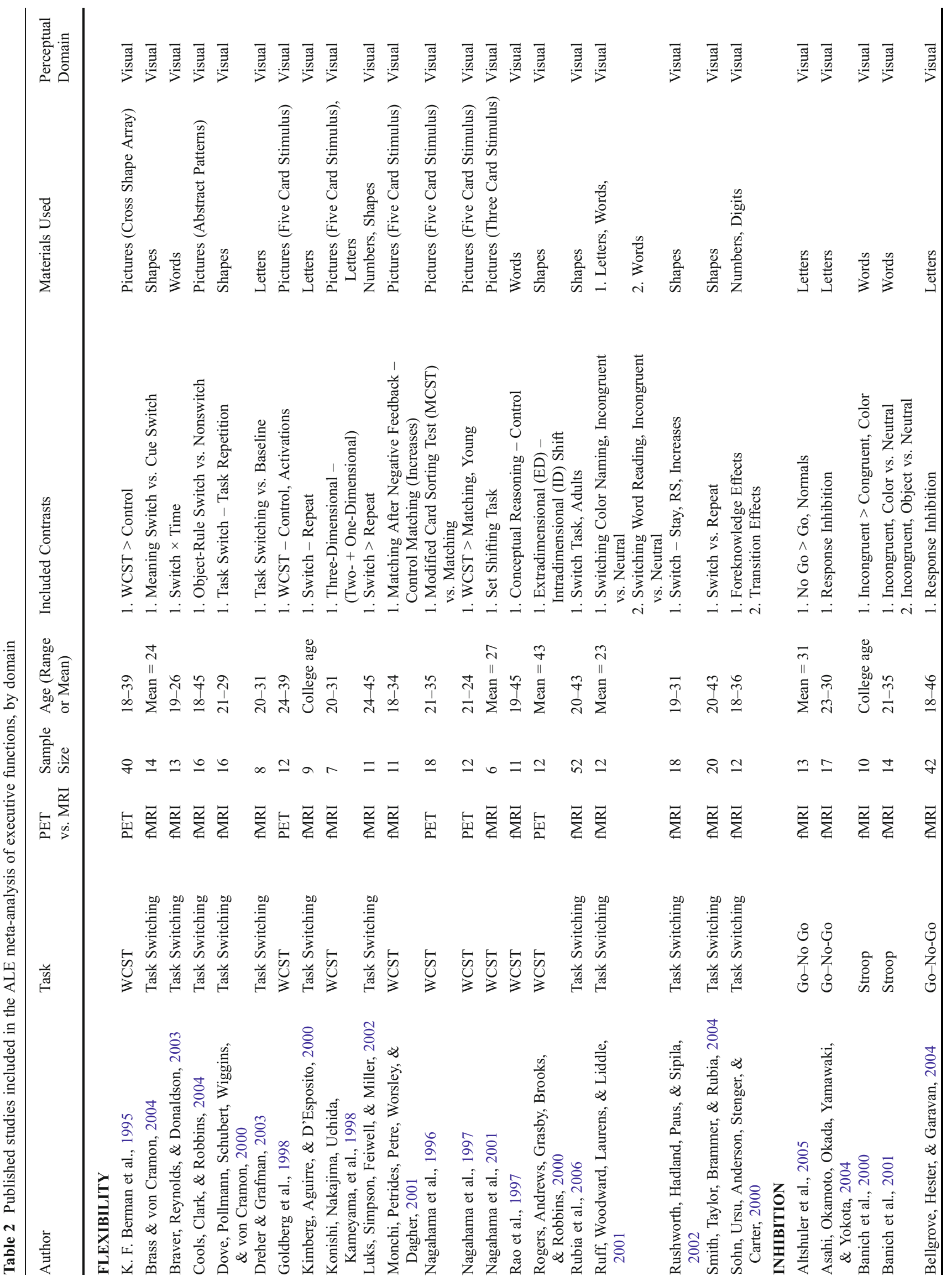




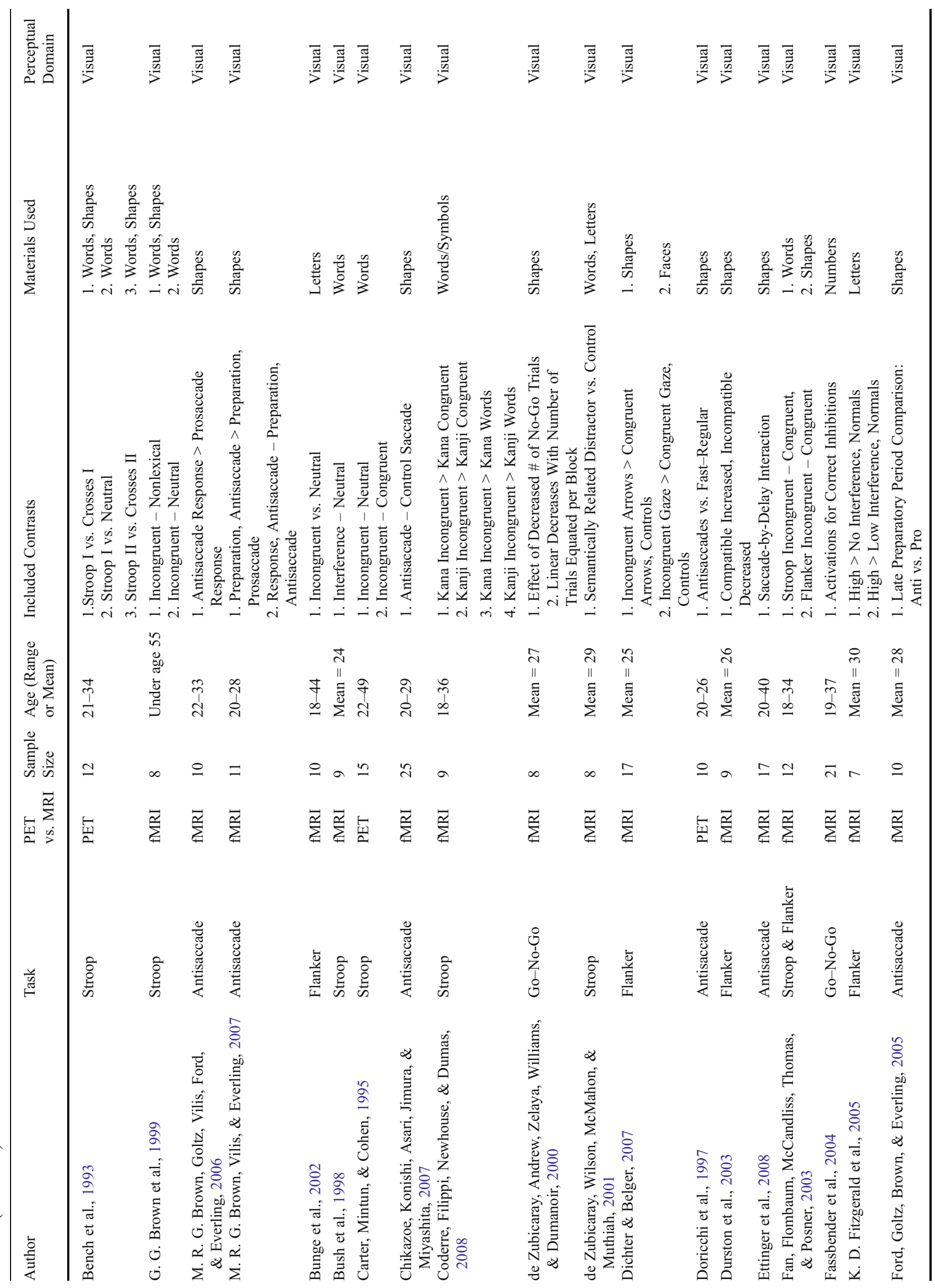




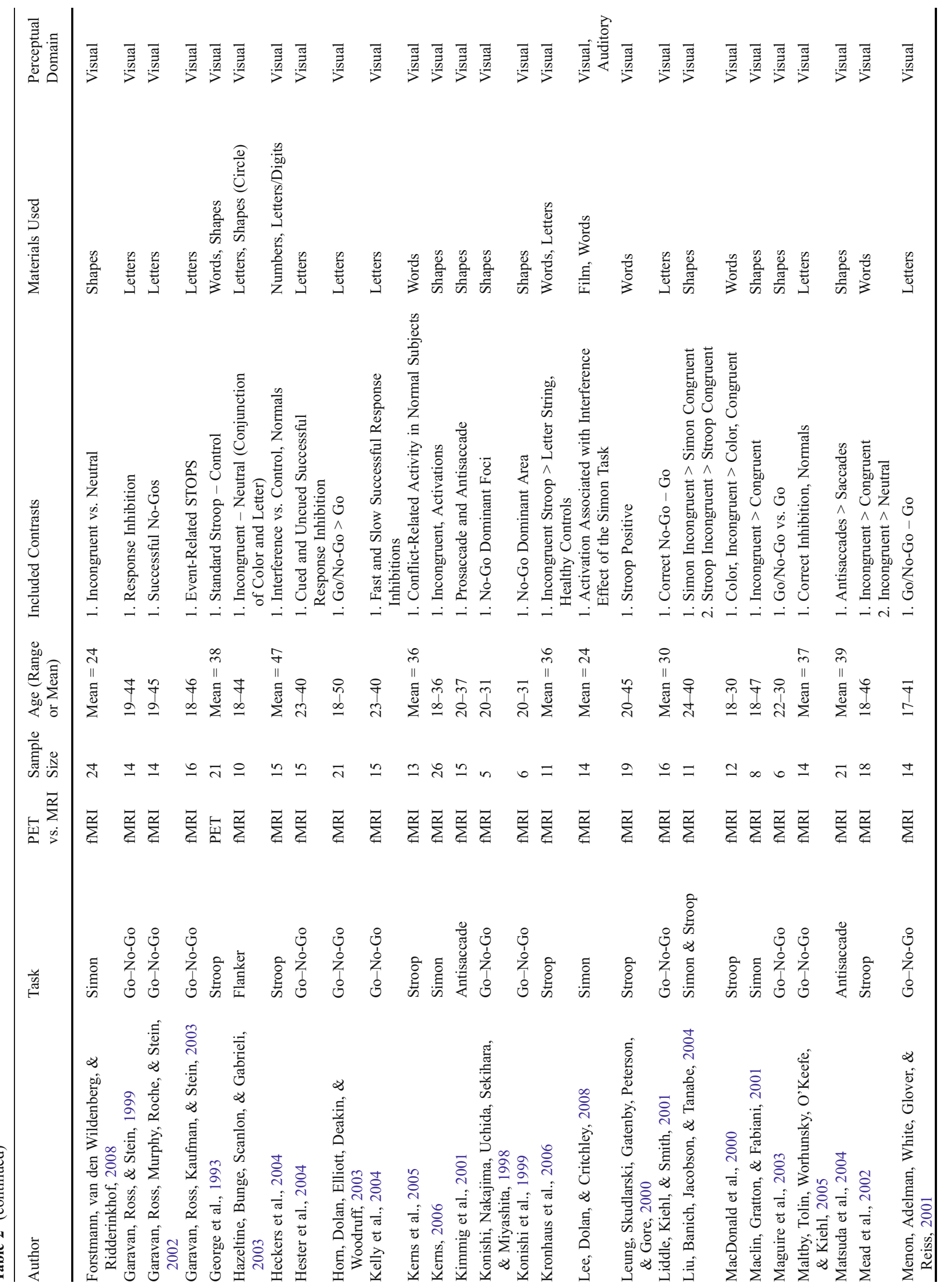




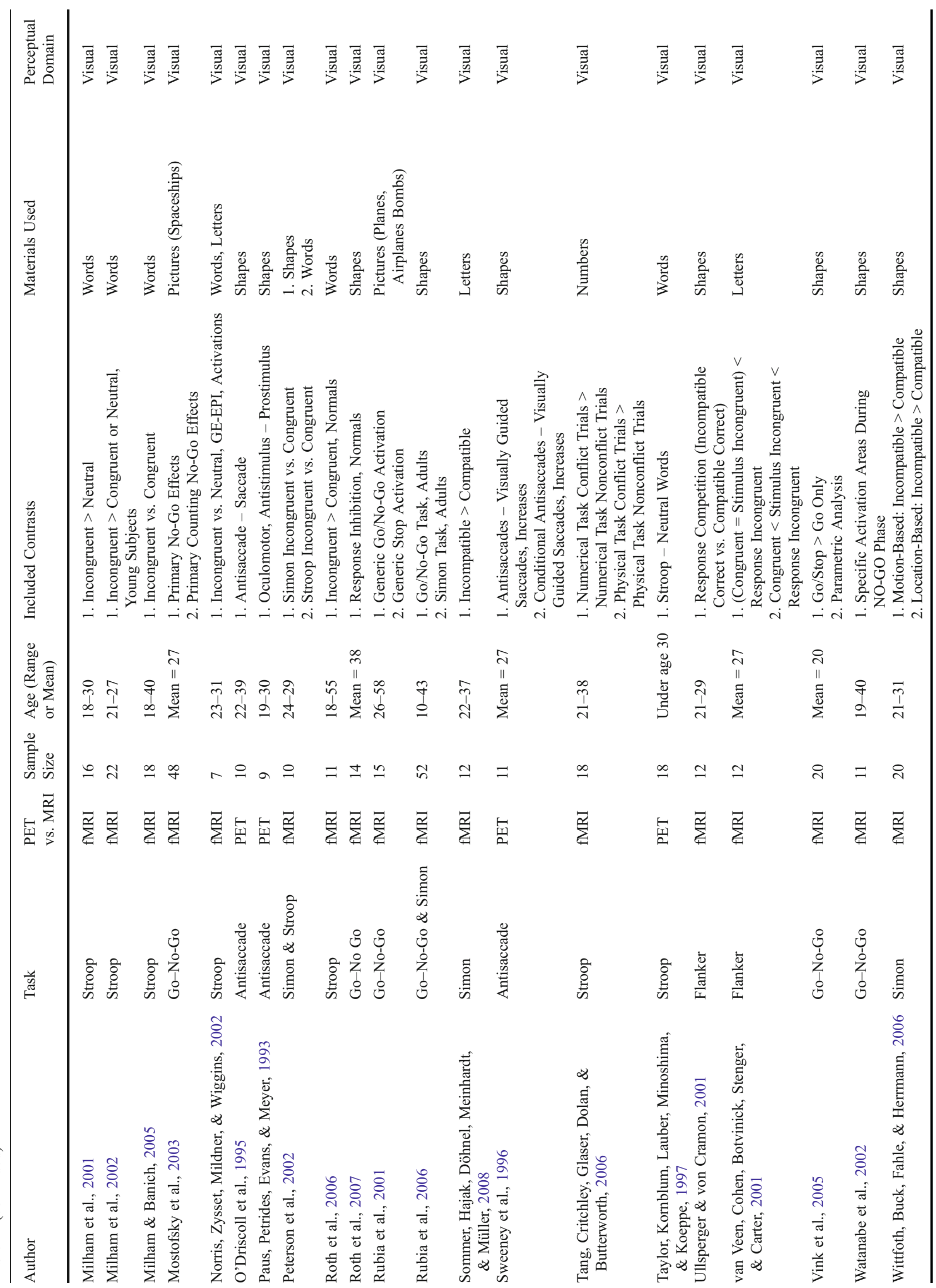




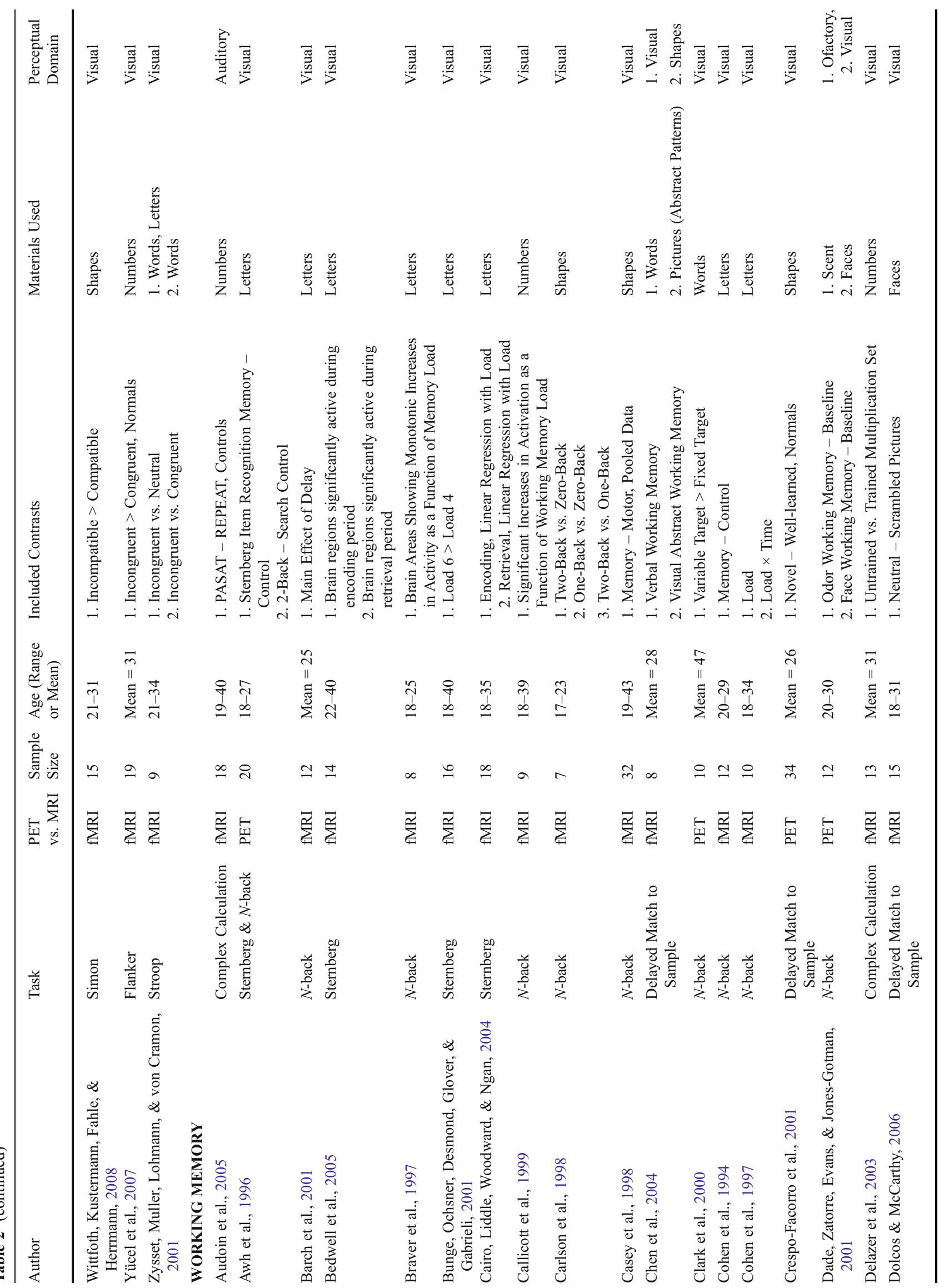




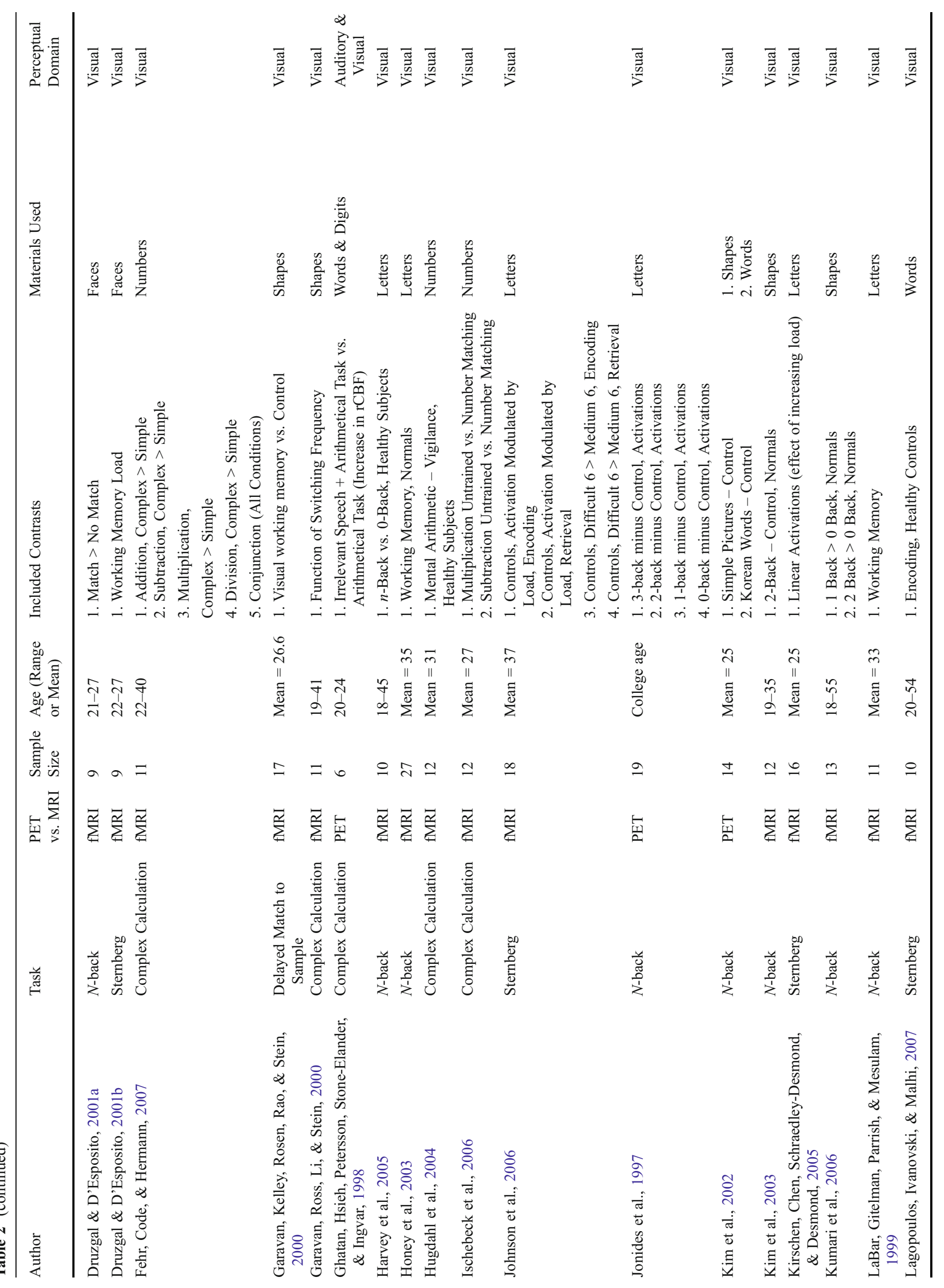




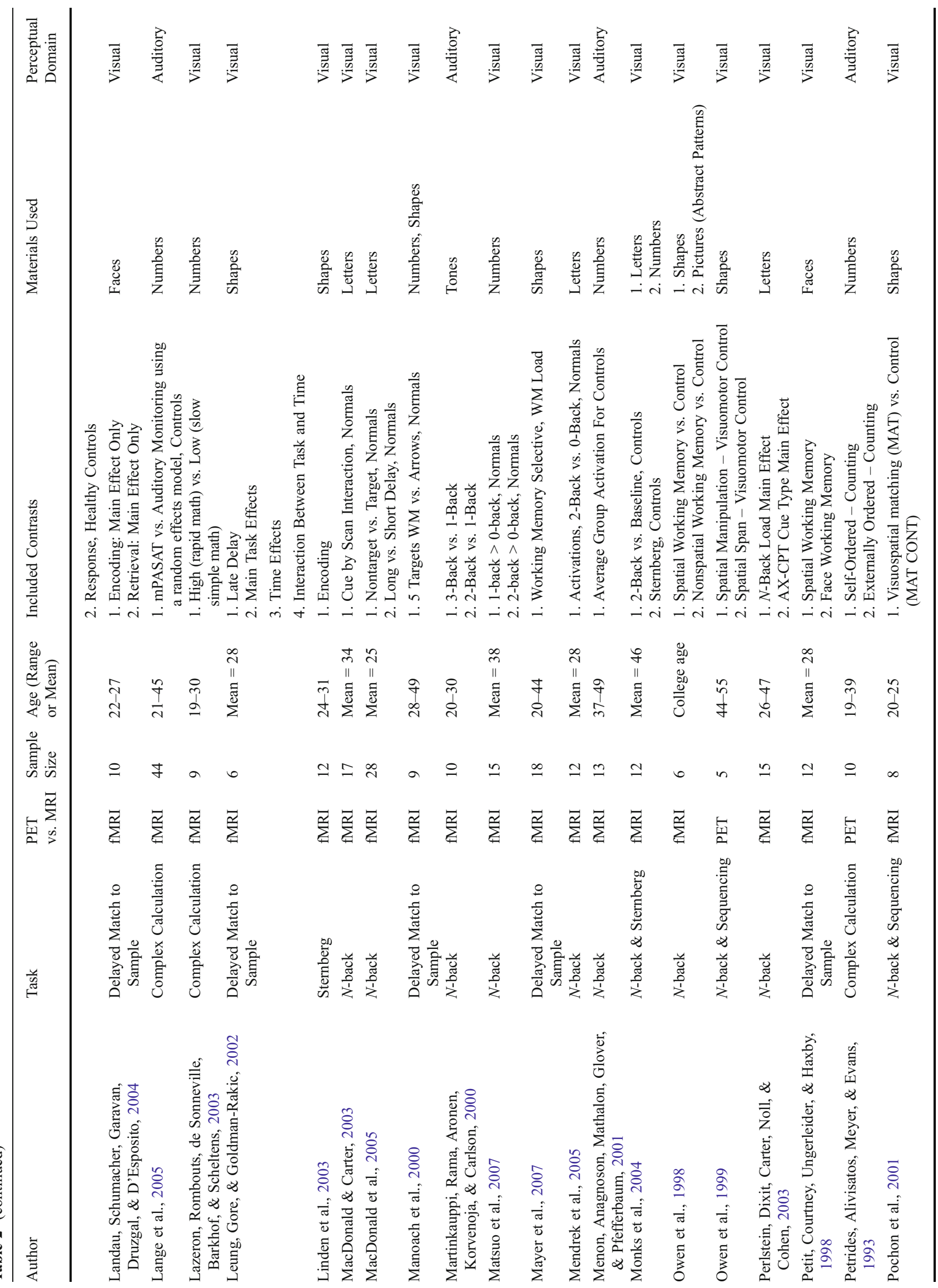




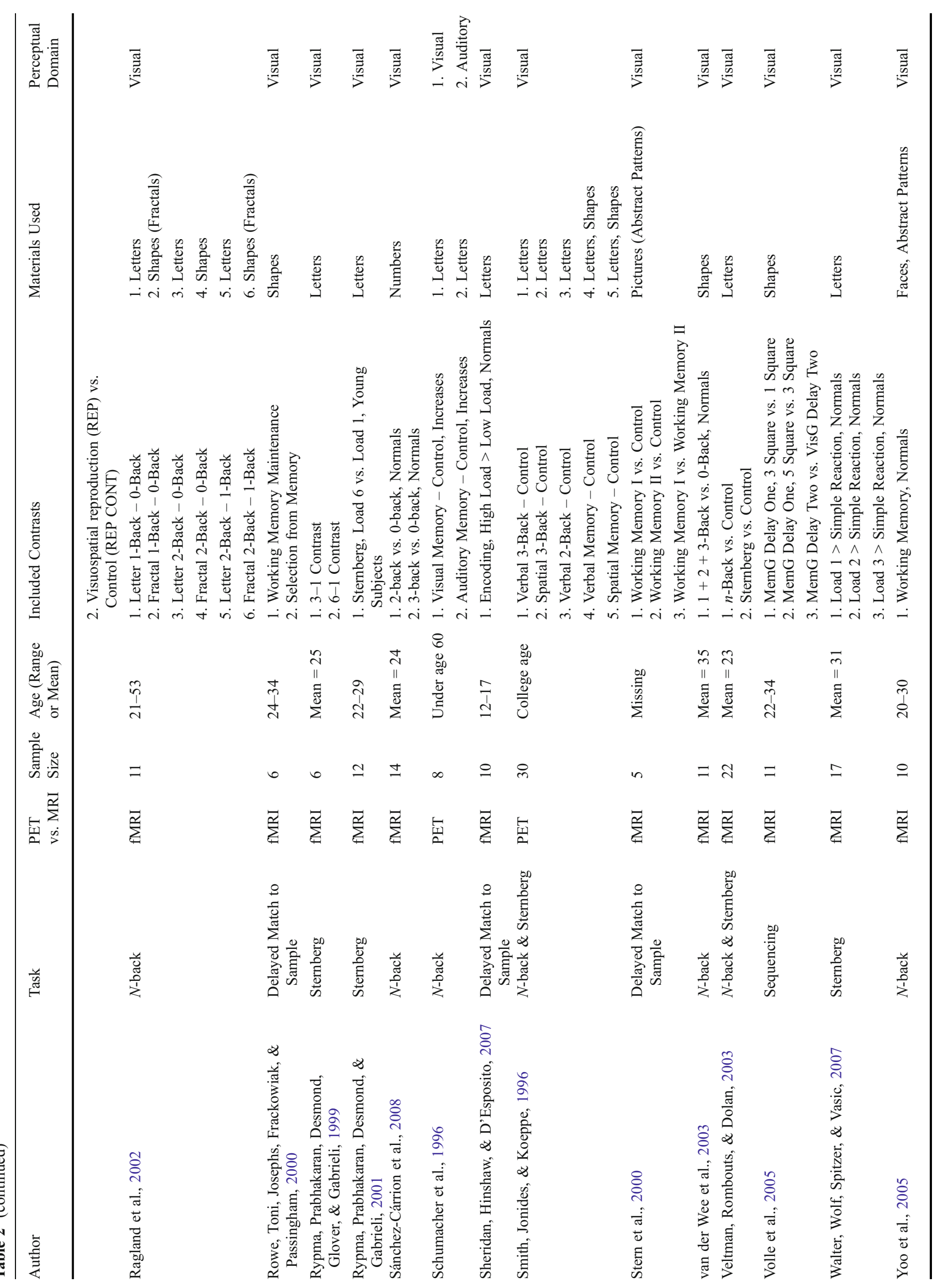




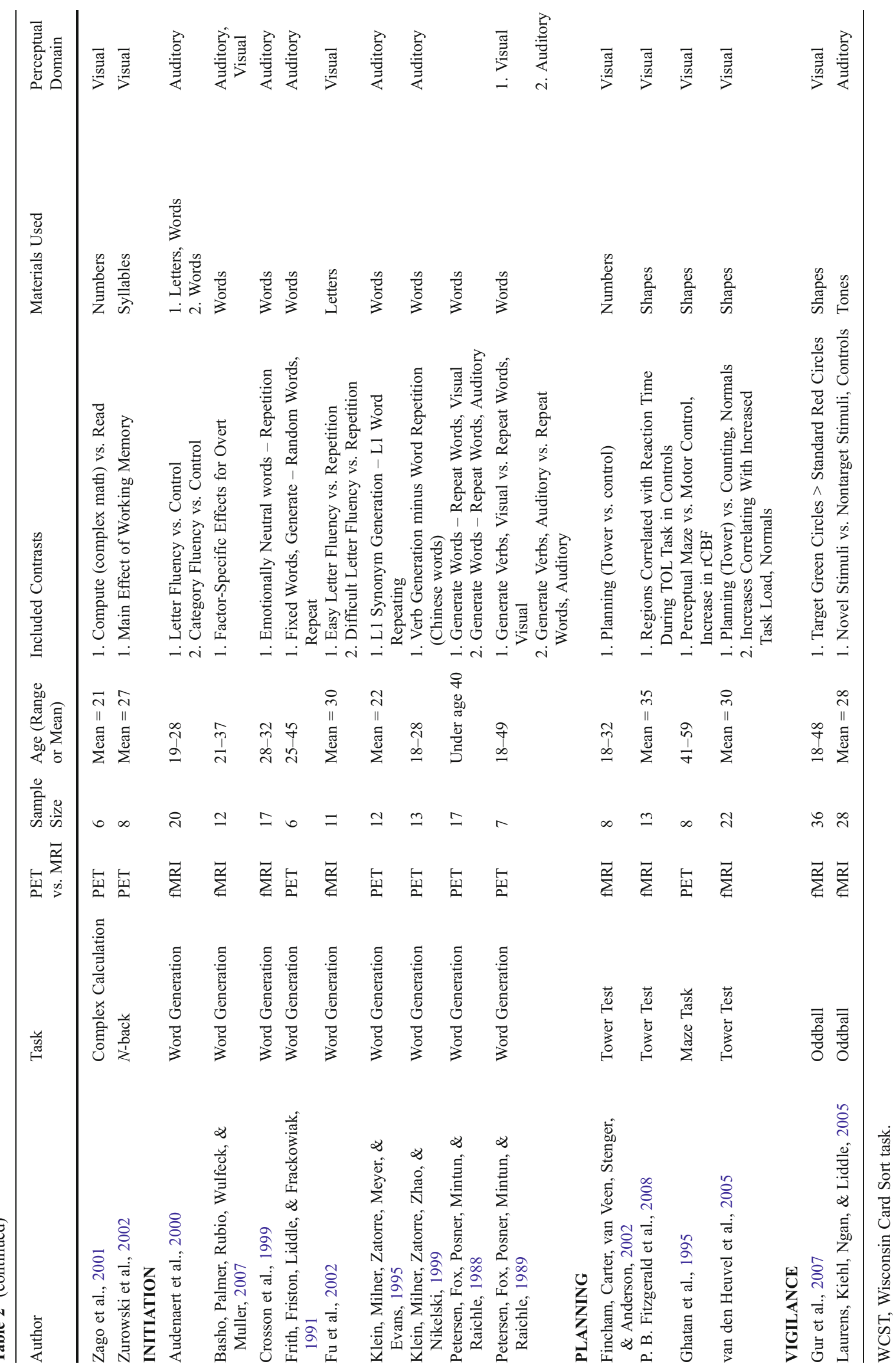




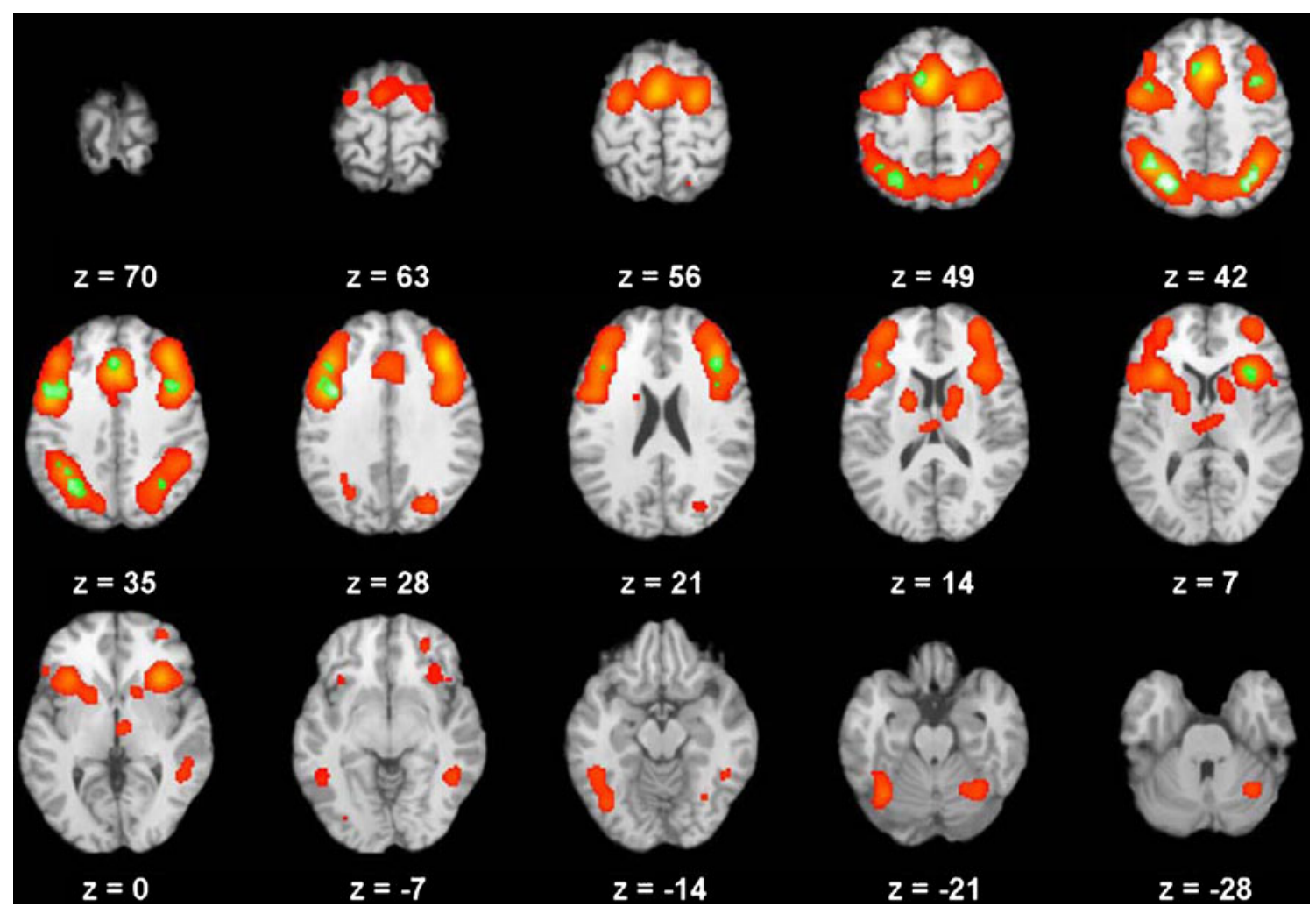

Fig. 1 Global analysis of executive function in 193 studies of healthy adults, showing brain regions with significant activation across all executive function domains (red) and the areas of conjunction (green) across the three domains for which data from more than nine studies were available (flexibility, inhibition, and working memory). activation was also observed in prefrontal (BAs 6, 10), occipital (BA 19), temporal (BAs 13, 37), and subcortical (thalamus, caudate, putamen, cerebellar declive) regions.

Other domains Domain-specific analyses for the planning and vigilance domains were not possible, due to the small number of studies available for inclusion within the ALE analysis (four and two studies, respectively). Although the number of studies for the initiation domain was also small $(n=9)$, the results are presented here as a preliminary analysis of site-specific activation within this domain. In contrast to the pattern of frontalparietal activation observed in the other three domains, initiation tasks were associated with a pattern of activation primarily in frontal regions, including the DLPFC (BA 46), middle (BA 10) and inferior (BA 47) frontal, anterior cingulate (BA 32), and motor (BA 6) regions, with no observed activation in parietal regions (see Fig. 2, Table 7). Activation was also observed in the superior (BA 21) and middle (BA 22) temporal, occipital (BA 17), and subcortical (putamen, caudate, cerebellar declive and culmen) regions, in a manner similar to other executive domains.

\section{Discussion}

Using a meta-analytic approach, we examined 193 neuroimaging studies of tasks divided according to classic executive function domains, creating the largest sample of healthy adults to date. We sought to provide evidence that discrete executive functions (initiation, inhibition, working memory, flexibility, planning, and vigilance) are supported by a shared, superordinate network that has been previously associated with cognitive control. Results of the combined analysis across domains showed that executive functions are indeed associated with increased activity in this common cognitive control network (Bellebaum \& Daum, 2007; Botvinick et al., 2001; Carter et al., 1999; Cohen et al., 2000; D'Esposito \& Postle, 2002; Yarkoni et al., 2005), which includes the DLPFC (BAs 9, 46), frontopolar cortex (BA 10), orbitofrontal cortex (BA 11), and anterior cingulate (BA 32). Additional concurrent regions of activation included the superior and inferior parietal (BAs 7, 40), occipital (BA 19), and temporal (BAs 13, 22, 37) cortex, as well as subcortical areas including the caudate, putamen, thalamus, and cerebellum. These conclusions were further supported by a conjunction analysis across the three domains in which data from more than nine studies were 
Table 3 Brain regions (Brodmann areas in parentheses) with significant activation within healthy adults from (a) a combined meta-analysis across all six executive function domains and (b) a conjunction meta-analysis for domains with more than nine included studies (flexibility, inhibition, and working memory)

\begin{tabular}{|c|c|c|c|c|}
\hline \multirow[b]{2}{*}{ Brain Region (BA) } & \multirow[b]{2}{*}{ Volume $\left(\mathrm{mm}^{3}\right)$} & \multicolumn{3}{|c|}{ Maxima } \\
\hline & & $x$ & $y$ & $z$ \\
\hline \multicolumn{5}{|l|}{ (a) Combined Across All Six Domains } \\
\hline Right Middle Frontal Gyrus (9) & 20,048 & 40 & 30 & 28 \\
\hline Right Insula (13) & & 32 & 18 & 4 \\
\hline Right Middle Frontal Gyrus (10) & & 32 & 48 & 14 \\
\hline Right Inferior Parietal Lobule (40) & 12,328 & 38 & -50 & 42 \\
\hline Right Superior Parietal Lobule (7) & & 32 & -60 & 42 \\
\hline Right Cuneus (19) & & 28 & -76 & 28 \\
\hline Left Superior Parietal Lobule (7) & 11,200 & -28 & -60 & 44 \\
\hline Right Precuneus (7) & & 8 & -68 & 46 \\
\hline Left Precuneus (7) & & -6 & -62 & 44 \\
\hline Left Superior Frontal Gyrus (6) & 9,112 & -2 & 6 & 50 \\
\hline Left Insula (13) & 6,744 & -32 & 18 & 6 \\
\hline Left Cerebellar Declive & 4,592 & -34 & -62 & -20 \\
\hline Left Fusiform Gyrus (37) & & -46 & -50 & -12 \\
\hline Left Middle Frontal Gyrus (10) & 3,608 & -36 & 44 & 18 \\
\hline Right Frontal Lobe Subgyral (6) & 3,032 & 26 & -2 & 54 \\
\hline Right Caudate Body & 2,984 & 16 & 2 & 12 \\
\hline Right Thalamus & & 12 & -8 & 14 \\
\hline Right Thalamus & & 6 & -16 & 2 \\
\hline Left Inferior Frontal Gyrus (9) & 2,776 & -42 & 4 & 30 \\
\hline Left Middle Frontal Gyrus (9) & 2,480 & -40 & 26 & 28 \\
\hline Right Cerebellar Culmen & 2,352 & 32 & -60 & -24 \\
\hline Left Middle Frontal Gyrus (6) & 1,936 & -28 & -4 & 50 \\
\hline Right Temporal Lobe Subgyral (37) & 1,912 & 46 & -52 & -6 \\
\hline Right Middle Temporal Gyrus (22) & & 50 & -42 & 2 \\
\hline Right Inferior Frontal Gyrus (9) & 1,080 & 44 & 6 & 32 \\
\hline Left Lentiform Nucleus Putamen & 1,016 & -20 & 8 & 4 \\
\hline Left Inferior Parietal Lobule (40) & 864 & -38 & -52 & 40 \\
\hline Right Caudate Head & 808 & 14 & 10 & 4 \\
\hline Right Cingulate Gyrus (32) & 704 & 2 & 16 & 40 \\
\hline Left Thalamus & 296 & -2 & -20 & 10 \\
\hline Right Middle Frontal Gyrus (11) & 224 & 26 & 42 & -10 \\
\hline Left Fusiform Gyrus (19) & 128 & -28 & -80 & -12 \\
\hline Left Lentiform Nucleus Putamen & 128 & -18 & -2 & 12 \\
\hline \multicolumn{5}{|l|}{ (b) Conjunction Analysis } \\
\hline \multicolumn{5}{|c|}{ (Flexibility, Inhibition, and Working Memory) } \\
\hline Left Superior Parietal Lobule (7) & 1,896 & -26 & -64 & 40 \\
\hline Left Inferior Frontal Gyrus (9) & 1,880 & -38 & 6 & 28 \\
\hline Left Middle Frontal Gyrus (9) & & -48 & 6 & 36 \\
\hline Left Middle Frontal Gyrus (9) & & -46 & 14 & 28 \\
\hline Left Middle Frontal Gyrus (9) & & -42 & 22 & 28 \\
\hline Right Inferior Parietal Lobule (39) & 856 & 34 & -62 & 40 \\
\hline Right Precuneus (19) & & 30 & -66 & 44 \\
\hline Right Middle Frontal Gyrus (6) & 576 & 34 & 8 & 42 \\
\hline Right Precentral Gyrus (9) & & 40 & 8 & 36 \\
\hline Left Inferior Parietal Lobule (40) & 568 & -38 & -52 & 44 \\
\hline Left Superior Frontal Gyrus (6) & 528 & -8 & 10 & 48 \\
\hline Left Cingulate Gyrus (32) & & -6 & 18 & 42 \\
\hline Right Middle Frontal Gyrus (46) & 432 & 40 & 26 & 22 \\
\hline
\end{tabular}




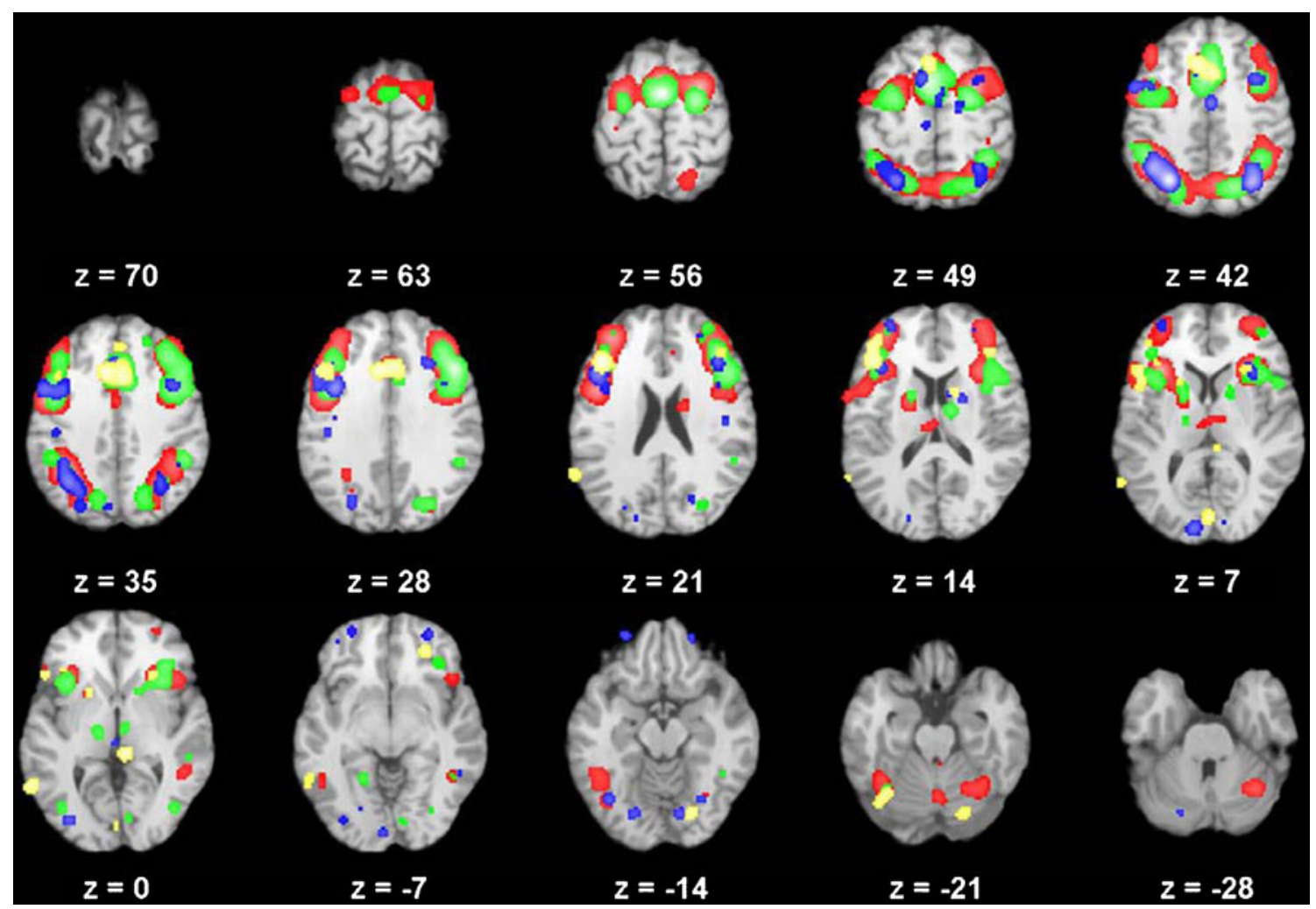

Fig. 2 Domain-specific analysis showing patterns of common and distinct activation across the working memory (red; 78 studies), inhibition (green; 79 studies), flexibility (blue; 21 studies), and initiation (yellow; 9 studies) domains

available (flexibility, inhibition, and working memory), which revealed a similar pattern of common activation in cognitivecontrol-related frontal and parietal regions. Although the present analysis did not directly examine the functional connectivity of these brain regions during each task, previous studies of cognitive control (Fornito et al., 2011; Yoon et al., 2008) have consistently shown task-related increases in functional connectivity between the DLPFC and the network of brain regions shown here.

These results provide additional evidence that a superordinate cognitive control network supports executive functions across a range of "domains" previously considered to be distinct, including flexibility, working memory, initiation, and inhibition. As proposed by Miller and Cohen (2001), it has been common to stress the distributed nature of the network that supports cognitive control functions, as well as the unique functional contributions by specific regions within the network. Within this framework, elements of the network may be differentially engaged, depending on the task demands. For example, previous studies (Spreng, Stevens, Chamberlain, Gilmore, \& Schacter, 2010; Vincent, Kahn, Snyder, Raichle, \& Buckner, 2008) have shown that the frontoparietal control network is engaged across multiple goal-directed activities, flexibly engaging the default-mode network to support autobiographical planning, or engaging the dorsal attention network to support visual spatial planning. Similarly, demands for specific goal- or task-contextrelated activity may be associated with stronger engagement of the PFC, and demands for maintaining information over longer periods of time may lead to more sustained network activity (Dosenbach et al., 2006; Yarkoni, Barch, Gray, Conturo, \& Braver, 2009). Its connectivity with sensory and motor regions, including the cerebellum, allows the DLPFC to play a central role in the maintenance of the rules for action, as well as response selection and inhibition (Asaad, Rainer, \& Miller, 2000; Bellebaum \& Daum, 2007; Watanabe, 1990, 1992). The ACC and related medial frontal regions are considered to support cognitive control by detecting conditions, such as processing conflicts, that indicate the demand for control, which then leads to the engagement of the DLPFC (Egner \& Hirsch, 2005; Kerns et al., 2005; MacDonald, Cohen, Stenger, \& Carter, 2000). Furthermore, parietal activation is considered to provide the DLPFC with information on stimulus salience and learned stimulus-response pairings, while the DLPFC is thought to support its ability to shift attentional focus according to the demands of the task at hand (Bunge, Hazeltine, Scanlon, Rosen, \& Gabrieli, 2002; Bunge, Kahn, Wallis, Miller, \& Wagner, 2003; Miller \& Cohen, 2001; Posner \& Petersen, 1990). 
Table 4 Brain regions (Brodmann areas in parentheses) with significant activation within healthy adults for tasks within the flexibility domain

\begin{tabular}{|c|c|c|c|c|}
\hline \multirow[b]{2}{*}{ Brain Region (BA) } & \multirow[b]{2}{*}{ Volume $\left(\mathrm{mm}^{3}\right)$} & \multicolumn{3}{|c|}{ Maxima } \\
\hline & & $x$ & $y$ & $z$ \\
\hline Left Inferior Frontal Gyrus (9) & 6,472 & -38 & 6 & 28 \\
\hline Left Middle Frontal Gyrus (46) & & -46 & 18 & 24 \\
\hline Left Middle Frontal Gyrus (9) & & -50 & 6 & 36 \\
\hline Left Middle Frontal Gyrus (46) & & -42 & 26 & 16 \\
\hline Left Superior Parietal Lobule (7) & 6,328 & -26 & -62 & 44 \\
\hline Left Inferior Parietal Lobule (40) & & -36 & -54 & 42 \\
\hline Left Precuneus (19) & & -26 & -78 & 32 \\
\hline Right Precuneus (19) & 2,648 & 32 & -64 & 42 \\
\hline Right Middle Frontal Gyrus (6) & 1,176 & 34 & 8 & 44 \\
\hline Right Precentral Gyrus (9) & & 40 & 8 & 36 \\
\hline Right Inferior Frontal Gyrus (9) & & 40 & 10 & 24 \\
\hline Right Middle Frontal Gyrus (46) & 856 & 40 & 26 & 22 \\
\hline Right Middle Frontal Gyrus (9) & & 28 & 24 & 30 \\
\hline Left Superior Frontal Gyrus (6) & 688 & -8 & 10 & 48 \\
\hline Left Cingulate Gyrus (32) & & -6 & 18 & 42 \\
\hline Right Cingulate Gyrus (24) & 584 & 4 & -8 & 44 \\
\hline Right Medial Frontal Gyrus (6) & & 6 & 0 & 48 \\
\hline Left Fusiform Gyrus (19) & 544 & -38 & -68 & -14 \\
\hline Left Cerebellar Declive & & -38 & -68 & -18 \\
\hline Left Cuneus (17) & 544 & -10 & -92 & 8 \\
\hline Left Middle Frontal Gyrus (10) & 464 & -32 & 52 & 10 \\
\hline Right Middle Frontal Gyrus (11) & 408 & 22 & 46 & -12 \\
\hline Right Middle Frontal Gyrus (10) & & 28 & 50 & -8 \\
\hline Left Middle Frontal Gyrus (11) & 408 & -26 & 48 & -12 \\
\hline Left Inferior Occipital Gyrus (18) & 368 & -32 & -82 & -2 \\
\hline Right Insula (13) & 344 & 32 & 18 & 8 \\
\hline Left Cerebellar Declive & 328 & -20 & -78 & -16 \\
\hline Left Cingulate Gyrus (32) & 296 & 0 & 26 & 36 \\
\hline Right Lentiform Nucleus Putamen & 272 & 20 & 0 & 14 \\
\hline Right Caudate Body & & 10 & 4 & 16 \\
\hline Left Postcentral Gyrus (2) & 240 & -42 & -24 & 30 \\
\hline Right Cerebellar Declive & 208 & 12 & -78 & -14 \\
\hline Right Medial Frontal Gyrus (6) & 208 & 18 & -10 & 52 \\
\hline Right Cuneus (18) & 152 & 24 & -76 & 16 \\
\hline Right Precuneus (31) & & 22 & -70 & 24 \\
\hline Left Middle Occipital Gyrus (18) & 144 & -18 & -86 & 16 \\
\hline Left Lingual Gyrus (18) & 136 & -4 & -90 & -8 \\
\hline Right Temporal Lobe Sub-Gyral (37) & 104 & 50 & -48 & -10 \\
\hline Left Paracentral Lobule (6) & 104 & -6 & -24 & 52 \\
\hline
\end{tabular}

Within the cognitive control network, it is likely that network-level subdivisions also exist and may be differentially engaged in the same manner. For example, Dosenbach, Fair, Cohen, Schlaggar, and Petersen (2008) proposed discrete circuits within this broader network that support task-sustained versus transient aspects of control, and that these networks may be differentially engaged across different forms of executive functions. Similarly, Braver, Paxton, Locke, and Barch (2009) emphasized that cognitive control has proactive and reactive elements. Proactive control may also depend more on sustained activity in the cognitive control network and, to the degree that 
Table 5 Brain regions (Brodmann areas in parentheses) with significant activation within healthy adults for tasks within the inhibition domain

\begin{tabular}{|c|c|c|c|c|}
\hline \multirow[b]{2}{*}{ Brain Region (BA) } & \multirow[b]{2}{*}{ Volume $\left(\mathrm{mm}^{3}\right)$} & \multicolumn{3}{|c|}{ Maxima } \\
\hline & & $x$ & $y$ & $z$ \\
\hline Right Middle Frontal Gyrus (9) & 20,464 & 46 & 20 & 28 \\
\hline Right Middle Frontal Gyrus (46) & & 40 & 32 & 24 \\
\hline Right Middle Frontal Gyrus (9) & & 38 & 28 & 32 \\
\hline Right Inferior Frontal Gyrus (9) & & 46 & 6 & 32 \\
\hline Right Precentral Gyrus (9) & & 38 & 6 & 38 \\
\hline Right Claustrum & & 32 & 16 & 2 \\
\hline Right Inferior Frontal Gyrus (47) & & 34 & 26 & 0 \\
\hline Right Precentral Gyrus (44) & & 50 & 10 & 8 \\
\hline Right Lentiform Nucleus Putamen & & 16 & 2 & 10 \\
\hline Right Lentiform Nucleus Putamen & & 16 & 8 & 2 \\
\hline Left Medial Frontal Gyrus (6) & 15,872 & 0 & -2 & 56 \\
\hline Left Medial Frontal Gyrus (32) & & 0 & 10 & 46 \\
\hline Left Precentral Gyrus (9) & 13,368 & -42 & 4 & 32 \\
\hline Left Middle Frontal Gyrus (6) & & -28 & -4 & 50 \\
\hline Left Middle Frontal Gyrus (9) & & -40 & 28 & 32 \\
\hline Left Insula (13) & & -36 & 12 & 4 \\
\hline Left Middle Frontal Gyrus (46) & & -38 & 30 & 12 \\
\hline Right Inferior Parietal Lobule (40) & 8,720 & 38 & -48 & 46 \\
\hline Right Precuneus (7) & & 18 & -68 & 42 \\
\hline Right Supramarginal Gyrus (40) & & 48 & -44 & 34 \\
\hline Right Cuneus (7) & & 20 & -74 & 32 \\
\hline Right Cuneus (19) & & 28 & -76 & 26 \\
\hline Right Angular Gyrus (39) & & 34 & -60 & 38 \\
\hline Right Superior Temporal Gyrus (13) & & 52 & -44 & 20 \\
\hline Left Precuneus (19) & 4,160 & -28 & -62 & 38 \\
\hline Left Precuneus (7) & & -20 & -70 & 42 \\
\hline Left Precuneus (7) & & -18 & -64 & 48 \\
\hline Left Precuneus (7) & & -12 & -72 & 34 \\
\hline Right Middle Frontal Gyrus (6) & 3,056 & 24 & -6 & 52 \\
\hline Left Inferior Parietal Lobule (40) & 2,408 & -44 & -44 & 40 \\
\hline Left Lentiform Nucleus Putamen & 912 & -18 & 8 & 4 \\
\hline Left Caudate Body & & -16 & 2 & 14 \\
\hline Left Thalamus Mammillary Body & 520 & -12 & -20 & 0 \\
\hline Right Thalamus & 456 & 12 & -10 & 14 \\
\hline Right Superior Frontal Gyrus (10) & 376 & 34 & 50 & 20 \\
\hline Right Middle Frontal Gyrus (10) & & 30 & 42 & 18 \\
\hline Right Inferior Frontal Gyrus (10) & 304 & 38 & 46 & 4 \\
\hline Right Inferior Occipital Gyrus (19) & 232 & 40 & -72 & 0 \\
\hline Left Inferior Occipital Gyrus (19) & 216 & -38 & -74 & 0 \\
\hline Right Lingual Gyrus (18) & 200 & 10 & -82 & -4 \\
\hline Left Parahippocampal Gyrus (19) & 192 & -18 & -52 & -6 \\
\hline Right Thalamus & 176 & 6 & -18 & 0 \\
\hline Left Cerebellar Declive & 160 & -34 & -62 & -20 \\
\hline Left Middle Frontal Gyrus (10) & 160 & -34 & 46 & 18 \\
\hline Right Superior Frontal Gyrus (9) & 160 & 22 & 40 & 34 \\
\hline
\end{tabular}


Table 6 Brain regions (Brodmann areas in parentheses) with significant activation within healthy adults within the working memory

\begin{tabular}{|c|c|c|c|c|}
\hline \multirow[b]{2}{*}{ Brain Region (BA) } & \multirow[b]{2}{*}{ Volume $\left(\mathrm{mm}^{3}\right)$} & \multicolumn{3}{|c|}{ Maxima } \\
\hline & & $x$ & $y$ & $z$ \\
\hline Right Middle Frontal Gyrus (9) & 103,712 & 38 & 30 & 28 \\
\hline Left Superior Frontal Gyrus (6) & & -2 & 6 & 52 \\
\hline Right Frontal Lobe Sub-Gyral (6) & & 26 & 2 & 54 \\
\hline Left Cingulate Gyrus (32) & & 0 & 16 & 40 \\
\hline Right Insula (13) & & 32 & 20 & 6 \\
\hline Left Inferior Frontal Gyrus (9) & & -44 & 6 & 26 \\
\hline Left Precentral Gyrus (6) & & -46 & 0 & 36 \\
\hline Left Insula (13) & & -32 & 18 & 6 \\
\hline Right Inferior Frontal Gyrus (9) & & 44 & 6 & 32 \\
\hline Left Middle Frontal Gyrus (6) & & -26 & -4 & 50 \\
\hline Left Middle Frontal Gyrus (9) & & -40 & 28 & 28 \\
\hline Left Middle Frontal Gyrus (10) & & -36 & 42 & 20 \\
\hline Left Middle Frontal Gyrus (46) & & -42 & 16 & 24 \\
\hline Left Lentiform Nucleus Putamen & & -18 & -4 & 12 \\
\hline Right Inferior Frontal Gyrus (47) & & 44 & 18 & -2 \\
\hline Left Precentral Gyrus (44) & & -48 & 14 & 8 \\
\hline Left Lentiform Nucleus Putamen & & -22 & 8 & 4 \\
\hline Left Middle Frontal Gyrus (10) & & -28 & 54 & 4 \\
\hline Left Cingulate Gyrus (24) & & 0 & -2 & 36 \\
\hline Left Precentral Gyrus (6) & & -60 & 2 & 14 \\
\hline Right Inferior Parietal Lobule (40) & 8,896 & 40 & -50 & 40 \\
\hline Right Cuneus (19) & & 28 & -76 & 30 \\
\hline Right Precuneus (7) & 8,152 & 10 & -66 & 46 \\
\hline Left Cerebellar Declive & 3,320 & -36 & -58 & -20 \\
\hline Left Fusiform Gyrus (37) & & -44 & -52 & -14 \\
\hline Left Cerebellar Declive & & -38 & -70 & -14 \\
\hline Right Cerebellar Tuber & 3,056 & 34 & -60 & -30 \\
\hline Left Thalamus & 864 & -4 & -20 & 12 \\
\hline Right Thalamus & & 8 & -14 & 4 \\
\hline Left Inferior Parietal Lobule (40) & 728 & -38 & -50 & 40 \\
\hline Right Cerebellar Declive & 448 & 2 & -64 & -22 \\
\hline Right Caudate Caudate Body & 264 & 16 & -6 & 20 \\
\hline
\end{tabular}

these systems may be segregated, they may be differentially engaged during executive functions. A study of the degree to which systematic differences exist in the engagement of discrete elements (regions or subnetworks) of the cognitive control networks across different executive function domains is beyond the resolution of this meta-analysis, and our understanding of this issue will be informed by future experimental studies, particularly those that include direct measures of intraregion connectivity or network dynamics across task demands.

While the use of quantitative meta-analytic methods allowed us to examine executive functions across a variety of tasks and domains within the largest sample of healthy adults to date, it is important to recognize that these findings are limited by the quality of the data available in the extant literature. Activation likelihood estimation requires the reporting of imaging data in three-dimensional coordinates in a standard brain space. Therefore, this analysis did not include studies in which such data were not reported for relevant contrasts (e.g., a within-subjects contrast related to the primary effect of interest in healthy controls), analyses that focused on particular regions of interest, or studies that reported negative findings, as the ALE method does not allow for the modeling of null results $(\mathrm{Li}, \mathrm{Chan}, \mathrm{McAlonan}$, \& Gong, 2010). Furthermore, the lack of appropriate contrasts, such as contrasting an active task with rest or fixation, reduced the number of studies available for inclusion within each domain. However, the use of an active control 
Table 7 Preliminary data for brain regions (Brodmann areas in parentheses) with significant activation within healthy adults for tasks within the initiation domain

\begin{tabular}{|c|c|c|c|c|}
\hline \multirow[b]{2}{*}{ Brain Region (BA) } & \multirow[b]{2}{*}{ Volume $\left(\mathrm{mm}^{3}\right)$} & \multicolumn{3}{|c|}{ Maxima } \\
\hline & & $x$ & $y$ & $z$ \\
\hline Left Cingulate Gyrus (32) & 6,064 & -6 & 18 & 32 \\
\hline Right Cingulate Gyrus (32) & & 4 & 14 & 38 \\
\hline Right Cingulate Gyrus (32) & & 2 & 22 & 30 \\
\hline Left Middle Frontal Gyrus (46) & 4,160 & -42 & 26 & 20 \\
\hline Left Inferior Frontal Gyrus (46) & & -42 & 38 & 12 \\
\hline Left Inferior Frontal Gyrus (45) & & -50 & 20 & 4 \\
\hline Left Precentral Gyrus (44) & & -46 & 12 & 8 \\
\hline Left Middle Temporal Gyrus (21) & 904 & -60 & -58 & 0 \\
\hline Right Cerebellar Declive & 632 & 22 & -76 & -16 \\
\hline Right Cerebellar Culmen & 584 & 6 & -36 & 2 \\
\hline Left Cerebellar Declive & 504 & -34 & -64 & -22 \\
\hline Right Occipital Lobe Lingual Gyrus (17) & 472 & 2 & -84 & 6 \\
\hline Right Middle Frontal Gyrus (46) & 384 & 42 & 32 & 18 \\
\hline Left Superior Temporal Gyrus (22) & 352 & -60 & -56 & 18 \\
\hline Right Claustrum & 344 & 26 & 20 & 2 \\
\hline Right Middle Frontal Gyrus (11) & 312 & 26 & 38 & -6 \\
\hline Left Lentiform Nucleus Putamen & 216 & -20 & 10 & 4 \\
\hline Right Caudate Body & 160 & 14 & 4 & 14 \\
\hline Right Medial Frontal Gyrus (6) & 128 & 2 & 36 & 34 \\
\hline Left Inferior Frontal Gyrus (45) & 120 & -36 & 24 & 4 \\
\hline
\end{tabular}

condition is essential in order to isolate the cognitive process of interest in subtraction contrasts (Stark \& Squire, 2001). Our approach to this analysis integrated findings from both fMRI and $\mathrm{O}^{15}$ PET studies, and the ALE method does not account for the potential influence of the different physiological signals associated with these two methods. Additionally, this method does not account for differences in behavioral performance across tasks or the influence of demographic factors, although the sample was restricted to studies that examined a specific age range (18-60 years). While all available studies within the BrainMap database were considered for this analysis, studies that were not included in the database at the time of the analysis have been omitted. Furthermore, this meta-analytic method does not allow for the weighting of results on the basis of levels of statistical significance or the numbers of activation foci that may have been reported by some studies within this investigation (Li, Chan, McAlonan, \& Gong, 2010). Although Gaussian blurring of the coordinates will have tended to remove per-study bias of the peak activation localizations, noise within the data might have influenced the study results (M. G. Berman et al., 2010). Finally, our definition of executive functions was based on a traditional view that is often used in cognitive or neuropsychological research (Lezak, 1995; Luria, 1970; Shallice, 1988), and the use of other definitions might have altered the domains examined.

In conclusion, the present study used the meta-analysis of a very large number of published fMRI data sets to examine whether traditional taxonomies of executive functions purporting discrete modular cognitive domains are supported by a superordinate cognitive control system that is engaged during the performance of a range of executive function tasks. Our results suggest that a frontal-cingulate-parietal-subcortical cognitive control network is consistently recruited across a range of traditional executive function tasks. Further research investigating the contributions of modular (e.g., prefrontal) versus shared elements (e.g., frontal-parietal connectivity) of the cognitive control network will inform our understanding of common and unique patterns of impairment in traditional executive functions that are often associated with various brain disorders. Novel approaches to investigating the function of different component systems using single methodologies (e.g., resting state; Deshpande, Santhanam, \& Hu, 2011) or combined methodologies (e.g., EEG and fMRI; Debener et al., 2005) have the potential to elucidated the complex brain dynamics underlying cognitive control. Further studies will be needed to make explicit the precise functional contributions of each individual element of the cognitive control network, as well as to understand the complex interactions between 
network nodes to support coordinated, goal-directed behavior. Through increased understanding of the function of modular components within this network, along with their anatomical connections and functional interactions, we will be able to more effectively investigate the mechanisms by which aberrant behavior or clinical symptoms may result from dysfunction in individual regions or in their connectivity within the broader network (Menon, 2011). Additional research on the relationship between various imaging modalities (e.g., resting state, task-related fMRI, or diffusion tensor imaging) will also help us to uncover ways in which discrete brain systems interact to support complex cognition and behavior.

Author note The authors acknowledge the National Institute of Mental Health for its support via Grants K23MH087708 to T.A.N., R01MH074457 to A.R.L., R01MH078143 and R01MH083824 to D. C.G., and 2R01MH059883 and 1R24MH081807 to C.S.C. The authors also thank the various researchers who responded to inquires about their sample demographics during the course of this analysis. The authors do not have any conflicts of interest to report in relation to this publication.

\section{References}

Altshuler, L. L., Bookheimer, S. Y., Townsend, J., Proenza, M. A., Eisenberger, N., Sabb, F., . . . Cohen, M. S. (2005). Blunted activation in orbitofrontal cortex during mania: A functional magnetic resonance imaging study. Biological Psychiatry, 58, 763-769. doi:10.1016/j.biopsych.2005.09.012.

Asaad, W. F., Rainer, G., \& Miller, E. K. (2000). Task-specific neural activity in the primate prefrontal cortex. Journal of Neurophysiology, 84, 451-459.

Asahi, S., Okamoto, Y., Okada, G., Yamawaki, S., \& Yokota, N. (2004). Negative correlation between right prefrontal activity during response inhibition and impulsiveness: A fMRI study. European Archives of Psychiatry and Clinical Neuroscience, 254, 245-251.

Audenaert, K., Brans, B., Van Laere, K., Lahorte, P., Versijpt, J., van Heeringen, K., \& Dierckx, R. (2000). Verbal fluency as a prefrontal activation probe: A validation study using $99 \mathrm{~m}$ Tc-ECD brain SPET. European Journal of Nuclear Medicine, 27, 1800-1808.

Audoin, B., Au Duong, M. V., Ranjeva, J. P., Ibarrola, D., Malikova, I., Confort-Gouny, S., . . . Cozzone, P. J. (2005). Magnetic resonance study of the influence of tissue damage and cortical reorganization on PASAT performance at the earliest stage of multiple sclerosis. Human Brain Mapping, 24, 216-228. doi:10.1002/hbm.20083.

Awh, E., Jonides, J., Smith, E. E., Schumacher, E. H., Koeppe, R. A., \& Katz, S. (1996). Dissociation of storage and rehearsal in verbal working memory: Evidence from positron emission tomography. Psychological Science, 7, 25-31.

Baddeley, A., \& Wilson, B. (1988). Frontal amnesia and the dysexecutive syndrome. Brain and Cognition, 7, 212-230.

Banich, M. (1997). Neuropsychology: The neural bases of mental function. Boston, MA: Houghton Mifflin.

Banich, M. T., Milham, M. P., Atchley, R. A., Cohen, N. J., Webb, A., Wszalek, T., . . . Brown, C. (2000). Prefrontal regions play a predominant role in imposing an attentional "set": Evidence from fMRI. Cognitive Brain Research, 10, 1-9. doi:10.1016/S09266410(00)00015-X
Banich, M. T., Milham, M. P., Jacobson, B. L., Webb, A., Wszalek, T., Cohen, N. J., \& Kramer, A. F. (2001). Attentional selection and the processing of task-irrelevant information: Insights from fMRI examinations of the Stroop task. Progress in Brain Research, 134, 459-470.

Barch, D. M., Carter, C. S., Braver, T. S., Sabb, F. W., MacDonald, A., III, Noll, D. C., \& Cohen, J. D. (2001). Selective deficits in prefrontal cortex function in medication-naive patients with schizophrenia. Archives of General Psychiatry, 58, 280-288.

Basho, S., Palmer, E. D., Rubio, M. A., Wulfeck, B., \& Muller, R. A. (2007). Effects of generation mode in fMRI adaptations of semantic fluency: Paced production and overt speech. Neuropsychologia, 45, 1697-1706.

Bedwell, J. S., Horner, M. D., Yamanaka, K., Li, X., Myrick, H., Nahas, Z., \& George, M. S. (2005). Functional neuroanatomy of subcomponent cognitive processes involved in verbal working memory. International Journal of Neuroscience, 115, 1017-1032. doi:10.1080/00207450590901530

Bellebaum, C., \& Daum, I. (2007). Cerebellar involvement in executive control. Cerebellum, 6, 184-192.

Bellgrove, M. A., Hester, R. L., \& Garavan, H. (2004). The functional neuroanatomical correlates of response variability: Evidence from a response inhibition task. Neuropsychologia, 42, 1910-1916.

Bench, C. J., Frith, C. D., Grasby, P. M., Friston, K. J., Paulesu, E., Frackowiak, R. S. J., \& Dolan, R. J. (1993). Investigations of the functional anatomy of attention using the Stroop test. Neuropsychologia, 31, 907-922.

Berman, K. F., Ostrem, J. L., Randolph, C., Gold, J., Goldberg, T. E., Coppola, R., . . W Weinberger, D. R. (1995). Physiological activation of a cortical network during performance of the Wisconsin Card Sorting Test: A positron emission tomography study. Neuropsychologia, 33, 1027-1046.

Berman, M. G., Park, J., Gonzalez, R., Polk, T. A., Gehrke, A., Knaffla, S., \& Jonides, J. (2010). Evaluating functional localizers: The case of the FFA. NeuroImage, 50, 56-71. doi:10.1016/j. neuroimage.2009.12.024

Binder, J. R., Desai, R. H., Graves, W. W., \& Conant, L. L. (2009). Where is the semantic system? A critical review and metaanalysis of 120 functional neuroimaging studies. Cerebral Cortex, 19, 2767-2796.

Botvinick, M. M., Braver, T. S., Barch, D. M., Carter, C. S., \& Cohen, J. D. (2001). Conflict monitoring and cognitive control. Psychological Review, 108, 624-652. doi:10.1037/0033-295X.108.3.624

Brass, M., \& von Cramon, D. Y. (2004). Decomposing components of task preparation with functional magnetic resonance imaging. Journal of Cognitive Neuroscience, 16, 609-620.

Braver, T. S., Cohen, J. D., \& Barch, D. M. (2002). The role of prefrontal cortex in normal and disordered cognitive control: A cognitive neuroscience perspective. New York, NY: Oxford University Press.

Braver, T. S., Cohen, J. D., Nystrom, L. E., Jonides, J., Smith, E. E., \& Noll, D. C. (1997). A parametric study of prefrontal cortex involvement in human working memory. Neurolmage, 5, 49-62.

Braver, T. S., Paxton, J. L., Locke, H. S., \& Barch, D. M. (2009). Flexible neural mechanisms of cognitive control within human prefrontal cortex. Proceedings of the National Academy of Sciences, 106, 7351-7356. doi:10.1073/pnas.0808187106

Braver, T. S., Reynolds, J. R., \& Donaldson, D. I. (2003). Neural mechanisms of transient and sustained cognitive control during task switching. Neuron, 39, 713-726.

Brown, M. R. G., Goltz, H. C., Vilis, T., Ford, K. A., \& Everling, S. (2006). Inhibition and generation of saccades: Rapid event-related fMRI of prosaccades, antisaccades, and no-go trials. NeuroImage, 33, 644-659.

Brown, G. G., Kindermann, S. S., Siegle, G. J., Granholm, E., Wong, E. C., \& Buxton, R. B. (1999). Brain activation and pupil 
response during covert performance of the Stroop color word task. Journal of the International Neuropsychological Society, 5, 308-319.

Brown, M. R. G., Vilis, T., \& Everling, S. (2007). Frontoparietal activation with preparation for antisaccades. Journal of Neurophysiology, 98, 1751-1762.

Bunge, S. A., Hazeltine, E., Scanlon, M. D., Rosen, A. C., \& Gabrieli, J. D. E. (2002). Dissociable contributions of prefrontal and parietal cortices to response selection. NeuroImage, 17, 1562-1571.

Bunge, S. A., Kahn, I., Wallis, J. D., Miller, E. K., \& Wagner, A. D. (2003). Neural circuits subserving the retrieval and maintenance of abstract rules. Journal of Neurophysiology, 90, 3419-3428.

Bunge, S. A., Ochsner, K. N., Desmond, J. E., Glover, G. H., \& Gabrieli, J. D. E. (2001). Prefrontal regions involved in keeping information in and out of mind. Brain, 124, 2074-2086.

Bush, G., Whalen, P. J., Rosen, B. R., Jenike, M. A., McInerney, S. C., \& Rauch, S. L. (1998). The counting Stroop: An interference task specialized for functional neuroimaging - Validation study with functional MRI. Human Brain Mapping, 6, 270-282.

Cairo, T. A., Liddle, P. F., Woodward, T. S., \& Ngan, E. T. C. (2004). The influence of working memory load on phase specific patterns of cortical activity. Cognitive Brain Research, 21, 377-387.

Callicott, J. H., Mattay, V. S., Bertolino, A., Finn, K., Coppola, R., Frank, J. A., . . . Weinberger, D. R. (1999). Physiological characteristics of capacity constraints in working memory as revealed by functional MRI. Cerebral Cortex, 9, 20-26.

Carlson, S., Martinkauppi, S., Rama, P., Salli, E., Korvenoja, A., \& Aronen, H. J. (1998). Distribution of cortical activation during visuospatial $n$-back tasks as revealed by functional magnetic resonance imaging. Cerebral Cortex, 8, 743-752.

Carter, C. S., Botvinick, M. M., \& Cohen, J. D. (1999). The contribution of the anterior cingulate cortex to executive processes in cognition. Reviews in the Neurosciences, 10, 49-57.

Carter, C. S., Braver, T. S., Barch, D. M., Botvinick, M. M., Noll, D., \& Cohen, J. D. (1998). Anterior cingulate cortex, error detection, and the online monitoring of performance. Science, 280, 747749

Carter, C. S., Mintun, M., \& Cohen, J. D. (1995). Interference and facilitation effects during selective attention: $\mathrm{An}_{2}{ }^{15} \mathrm{O}$ PET study of Stroop task performance. NeuroImage, 2, 264-272.

Casey, B. J., Cohen, J. D., O'Craven, K., Davidson, R. J., Irwin, W., Nelson, C. A., . . Turski, P. A. (1998). Reproducibility of fMRI results across four institutions using a spatial working memory task. NeuroImage, 8, 249-261.

Caspers, S., Zilles, K., Laird, A. R., \& Eickhoff, S. B. (2010). ALE meta-analysis of action observation and imitation in the human brain. NeuroImage, 50, 1148-1167. doi:10.1016/j. neuroimage.2009.12.112

Chen, J. K., Johnston, K. M., Frey, S., Petrides, M., Worsley, K. J., \& Ptito, A. (2004). Functional abnormalities in symptomatic concussed athletes: An fMRI study. NeuroImage, 22, 68-82.

Chikazoe, J., Konishi, S., Asari, T., Jimura, K., \& Miyashita, Y. (2007). Activation of right inferior frontal gyrus during response inhibition across response modalities. Journal of Cognitive Neuroscience, 19, 69-80.

Chouinard, P. A., \& Goodale, M. A. (2010). Category-specific neural processing for naming pictures of animals and naming pictures of tools: An ALE meta-analysis. Neuropsychologia, 48, 409-418.

Clark, C. R., Egan, G. F., McFarlane, A. C., Morris, P., Weber, D., Sonkkilla, C., . . . Danguy, H. J. (2000). Updating working memory for words: A PET activation study. Human Brain Mapping, 9, 42-54.

Coderre, E. L., Filippi, C. G., Newhouse, P. A., \& Dumas, J. A. (2008). The Stroop effect in kana and kanji scripts in native Japanese speakers: An fMRI study. Brain and Language, 107, 124-132.
Cohen, J. D., Botvinick, M., \& Carter, C. S. (2000). Anterior cingulate and prefrontal cortex: Who's in control? Nature Neuroscience, 3, 421-423. doi:10.1038/74783

Cohen, J. D., Dunbar, K., \& McClelland, J. L. (1990). On the control of automatic processes: A parallel distributed processing account of the Stroop effect. Psychological Review, 97, 332-361.

Cohen, J. D., Forman, S. D., Braver, T. S., Casey, B. J., ServanSchreiber, D., \& Noll, D. C. (1994). Activation of the prefrontal cortex in a nonspatial working memory task with functional MRI. Human Brain Mapping, 1, 293-304.

Cohen, J. D., Perlstein, W. M., Braver, T. S., Nystrom, L. E., Noll, D. C., Jonides, J., \& Smith, E. E. (1997). Temporal dynamics of brain activation during a working memory task. Nature, 386, 604-608.

Cools, R., Clark, L., \& Robbins, T. W. (2004). Differential responses in human striatum and prefrontal cortex to changes in object and rule relevance. Journal of Neuroscience, 24, 1129-1135.

Crespo-Facorro, B., Wiser, A. K., Andreasen, N. C., O'Leary, D. S., Watkins, G. L., Boles Ponto, L. L., \& Hichwa, R. D. (2001). Neural basis of novel and well-learned recognition memory in schizophrenia: A positron emission tomography study. Human Brain Mapping, 12, 219-231.

Crosson, B., Radonovich, K., Sadek, J. R., Gökçay, D., Bauer, R. M., Fischler, I. S., . . . Briggs, R. W. (1999). Lefthemisphere processing of emotional connotation during word generation. NeuroReport, 10, 2449-2455.

D'Esposito, M. (2007). From cognitive to neural models of working memory. Philosophical Transactions of the Royal Society B, 362, 761-772.

D'Esposito, M., \& Postle, B. R. (2002). The neural basis of working memory storage, rehearsal, and control processes: Evidence from patient and functional magnetic resonance imaging studies. New York, NY: Guilford Press.

Dade, L. A., Zatorre, R. J., Evans, A. C., \& Jones-Gotman, M. (2001). Working memory in another dimension: Functional imaging of human olfactory working memory. NeuroImage, 14, 650-660.

de Zubicaray, G. I., Andrew, C. M., Zelaya, F. O., Williams, S. C. R., \& Dumanoir, C. (2000). Motor response suppression and the prepotent tendency to respond: A parametric fMRI study. Neuropsychologia, $38,1280-1291$.

de Zubicaray, G. I., Wilson, S. J., McMahon, K. L., \& Muthiah, S. (2001). The semantic interference effect in the picture-word paradigm: An event-related fMRI study employing overt responses. Human Brain Mapping, 14, 218-227.

Debener, S., Ullsperger, M., Siegel, M., Fiehler, K., von Cramon, D. Y., \& Engel, A. K. (2005). Trial-by-trial coupling of concurrent electroencephalogram and functional magnetic resonance imaging identifies the dynamics of performance monitoring. Journal of Neuroscience, 25, 11730-11737.

Delazer, M., Domahs, F., Bartha, L., Brenneis, C., Lochy, A., Trieb, T., \& Benke, T. (2003). Learning complex arithmetic-An fMRI study. Cognitive Brain Research, 18, 76-88.

Deshpande, G., Santhanam, P., \& Hu, X. (2011). Instantaneous and causal connectivity in resting state brain networks derived from functional MRI data. NeuroImage, 54, 1043-1052.

Dichter, G. S., \& Belger, A. (2007). Social stimuli interfere with cognitive control in autism. NeuroImage, 35, 1219-1230.

Dickstein, S. G., Bannon, K., Castellanos, F. X., \& Milham, M. P. (2006). The neural correlates of attention deficit hyperactivity disorder: An ALE meta-analysis. Journal of Child Psychology and Psychiatry, 47, 1051-1062. doi:10.1111/j.1469-7610.2006.01671.x

Dolcos, F., \& McCarthy, G. (2006). Brain systems mediating cognitive interference by emotional distraction. Journal of Neuroscience, 26, 2072-2079.

Doricchi, F., Perani, D., Incoccia, C., Grassi, F., Cappa, S. F., Bettinardi, V., . . Fazio, F. (1997). Neural control of fast-regular saccades and 
antisaccades: An investigation using positron emission tomography. Experimental Brain Research, 116, 50-62.

Dosenbach, N. U., Fair, D. A., Cohen, A. L., Schlaggar, B. L., \& Petersen, S. E. (2008). A dual-networks architecture of top-down control. Trends in Cognitive Sciences, 12, 99-105.

Dosenbach, N. U., Visscher, K. M., Palmer, E. D., Miezin, F. M., Wenger, K. K., Kang, H. C., . . Petersen, S. E. (2006). A core system for the implementation of task sets. Neuron, 50, 799-812. doi:10.1016/j.neuron.2006.04.031

Dove, A., Pollmann, S., Schubert, T., Wiggins, C. J., \& von Cramon, D. Y. (2000). Prefrontal cortex activation in task switching: An event-related fMRI study. Cognitive Brain Research, 9, 103-109.

Dreher, J. C., \& Grafman, J. (2003). Dissociating the roles of the rostral anterior cingulate and the lateral prefrontal cortices in performing two tasks simultaneously or successively. Cerebral Cortex, 13, 329-339.

Druzgal, T. J., \& D'Esposito, M. (2001a). Activity in fusiform face area modulated as a function of working memory load. Cognitive Brain Research, 10, 355-364.

Druzgal, T. J., \& D'Esposito, M. (2001b). A neural network reflecting decisions about human faces. Neuron, 32, 947-955.

Duncan, J., \& Owen, A. M. (2000). Common regions of the human frontal lobe recruited by diverse cognitive demands. Trends in Neurosciences, 23, 475-483.

Durston, S., Davidson, M. C., Thomas, K. M., Worden, M. S., Tottenham, N., Martinez, A., . . Casey, B. J. (2003). Parametric manipulation of conflict and response competition using rapid mixed-trial eventrelated fMRI. NeuroImage, 20, 2135-2141.

Egner, T., \& Hirsch, J. (2005). Cognitive control mechanisms resolve conflict through cortical amplification of task-relevant information. Nature Neuroscience, 8, 1784-1790.

Eickhoff, S. B., Laird, A. R., Grefkes, C., Wang, L. E., Zilles, K., \& Fox, P. T. (2009). Coordinate-based activation likelihood estimation meta-analysis of neuroimaging data: A random-effects approach based on empirical estimates of spatial uncertainty. Human Brain Mapping, 30, 2907-2926.

Ettinger, U., Ffytche, D. H., Kumari, V., Kathmann, N., Reuter, B., Zelaya, F., \& Williams, S. C. (2008). Decomposing the neural correlates of antisaccade eye movements using event-related fMRI. Cerebral Cortex, 18, 1148-1159. doi:10.1093/cercor/ bhm147

Fan, J., Flombaum, J. I., McCandliss, B. D., Thomas, K. M., \& Posner, M. I. (2003). Cognitive and brain consequences of conflict. Neurolmage, 18, 42-57.

Fassbender, C., Murphy, K., Foxe, J. J., Wylie, G. R., Javitt, D. C., Robertson, I. H., \& Garavan, H. (2004). A topography of executive functions and their interactions revealed by functional magnetic resonance imaging. Cognitive Brain Research, 20, 132-143. doi:10.1016/j.cogbrainres.2004.02.007

Fehr, T., Code, C., \& Hermann, M. (2007). Common brain regions underlying different arithmetic operations as revealed by conjunct fMRI-BOLD activation. Brain Research, 1172, 93-102.

Fincham, J. M., Carter, C. S., van Veen, V., Stenger, V. A., \& Anderson, J. R. (2002). Neural mechanisms of planning: A computational analysis using event-related fMRI. Proceedings of the National Academy of Sciences, 99, 3346-3351.

Fitzgerald, P. B., Srithiran, A., Benitez, J., Daskalakis, Z. Z., Oxley, T. J., Kulkarni, J., \& Egan, G. F. (2008). An fMRI study of prefrontal brain activation during multiple tasks in patients with major depressive disorder. Human Brain Mapping, 29, 490-501. doi:10.1002/hbm.20414

Fitzgerald, K. D., Welsh, R. C., Gehring, W. J., Abelson, J. L., Himle, J. A., Liberzon, I., \& Taylor, S. F. (2005). Error-related hyperactivity of the anterior cingulate cortex in obsessive-compulsive disorder. Biological Psychiatry, 57, 287-294. doi:10.1016/j. biopsych.2004.10.038
Ford, K. A., Goltz, H. C., Brown, M. R. G., \& Everling, S. (2005). Neural processes associated with antisaccade task performance investigated with event-related fMRI. Journal of Neurophysiology, 94, 429-440.

Fornito, A., Yoon, J., Zalesky, A., Bullmore, E. T., \& Carter, C. S. (2011). General and specific functional connectivity disturbances in first-episode schizophrenia during cognitive control performance. Biological Psychiatry, 70, 64-72.

Forstmann, B. U., van den Wildenberg, W. P. M., \& Ridderinkhof, K. R. (2008). Neural mechanisms, temporal dynamics, and individual differences in interference control. Journal of Cognitive Neuroscience, 20, 1854-1865.

Fox, P. T., \& Lancaster, J. L. (2002). Mapping context and content: The BrainMap model. Nature Reviews Neuroscience, 3, 319-321.

Frith, C. D., Friston, K. J., Liddle, P. F., \& Frackowiak, R. S. J. (1991). Willed action and the prefrontal cortex in man: A study with PET. Proceedings of the Royal Society B, 244, 241-246.

Fu, C. H. Y., Morgan, K., Suckling, J., Williams, S. C. R., Andrew, C., Vythelingum, G. N., \& McGuire, P. K. (2002). A functional magnetic resonance imaging study of overt letter verbal fluency using a clustered acquisition sequence: Greater anterior cingulate activation with increased task demand. NeuroImage, 17, 871-879.

Fusar-Poli, P., Placentino, A., Carletti, F., Allen, P., Landi, P., Abbamonte, M., . . . Politi, P. L. (2009). Laterality effect on emotional faces processing: ALE meta-analysis of evidence. Neuroscience Letters, 452, 262-267. doi:10.1016/j.neulet.2009.01.065

Fuster, J. M. (1990). Behavioral electrophysiology of the prefrontal cortex of the primate. Progress in Brain Research, 85, 313-324.

Fuster, J. M. (2002). Frontal lobe and cognitive development. Journal of Neurocytology, 31, 373-385.

Garavan, H., Kelley, D., Rosen, A. C., Rao, S. M., \& Stein, E. A. (2000a). Practice-related functional activation changes in a working memory task. Microscopy Research and Technique, $51,54-63$.

Garavan, H., Ross, T. J., Kaufman, J. N., \& Stein, E. A. (2003). A midline dissociation between error-processing and responseconflict monitoring. NeuroImage, 20, 1132-1139.

Garavan, H., Ross, T. J., Li, S. J., \& Stein, E. A. (2000b). A parametric manipulation of central executive functioning. Cerebral Cortex, 10, 585-592.

Garavan, H., Ross, T. J., Murphy, K., Roche, R. A. P., \& Stein, E. A. (2002). Dissociable executive functions in the dynamic control of behavior: Inhibition, error detection, and correction. NeuroImage, 17, 1820-1829.

Garavan, H., Ross, T. J., \& Stein, E. A. (1999). Right hemispheric dominance of inhibitory control: An event-related functional MRI study. Proceedings of the National Academy of Sciences, 96, 8301-8306.

George, M. S., Ketter, T. A., Parekh, P. I., Rosinsky, N., Ring, H., Casey, B. J., . . . Post, R. M. (1993). Regional brain activity when selecting a response despite interference: $\mathrm{An}_{2}{ }^{15} \mathrm{O}$ PET study of the Stroop and an emotional Stroop. Human Brain Mapping, 1, 194-209. doi: $10.1002 / \mathrm{hbm} .460010305$

Ghatan, P. H., Hsieh, J. C., Petersson, K. M., Stone-Elander, S., \& Ingvar, M. (1998). Coexistence of attention-based facilitation and inhibition in the human cortex. NeuroImage, 7, 23-29.

Ghatan, P. H., Hsieh, J. C., Wirsén-Meurling, A., Wredling, R., Eriksson, L., Stone-Elander, S., . . Ingvar, M. (1995). Brain activation induced by the perceptual maze test: A PET study of cognitive performance. Neurolmage, 2, 112-124.

Glahn, D. C., Ragland, J. D., Abramoff, A., Barrett, J., Laird, A. R., Bearden, C. E., \& Velligan, D. I. (2005). Beyond hypofrontality: A quantitative meta-analysis of functional neuroimaging studies of working memory in schizophrenia. Human Brain Mapping, 25, 60-69. doi:10.1002/hbm.20138 
Goghari, V. M. (2010). Executive functioning-related brain abnormalities associated with the genetic liability for schizophrenia: An activation likelihood estimation meta-analysis. Psychological Medicine, 1-14.

Goldberg, T. E., Berman, K. F., Fleming, K., Ostrem, J., Van Horn, J. D., Esposito, G., . . . Weinberger, D. R. (1998). Uncoupling cognitive workload and prefrontal cortical physiology: A PET rCBF study. NeuroImage, 7, 296-303.

Goldman-Rakic, P. S. (1987). Development of cortical circuitry and cognitive function. Child Development, 58, 601-622.

Goldman-Rakic, P. S. (1996). Regional and cellular fractionation of working memory. Proceedings of the National Academy of Sciences, 93, 13473-13480.

Gur, R. C., Turetsky, B. I., Loughead, J., Waxman, J., Snyder, W., Ragland, J. D., . . . Gur, R. E. (2007). Hemodynamic responses in neural circuitries for detection of visual target and novelty: An event-related fMRI study. Human Brain Mapping, 28, 263-274. doi:10.1002/hbm.20319

Harvey, P.-O., Fossati, P., Pochon, J.-B., Levy, R., LeBastard, G., Lehéricy, S., . . . Dubois, B. (2005). Cognitive control and brain resources in major depression: An fMRI study using the $n$-back task. NeuroImage, 26, 860-869. doi:10.1016/j. neuroimage.2005.02.048

Hazeltine, E., Bunge, S. A., Scanlon, M. D., \& Gabrieli, J. D. E. (2003). Material-dependent and material-independent selection processes in the frontal and parietal lobes: An event-related fMRI investigation of response competition. Neuropsychologia, 41, $1208-1217$.

Heckers, S., Weiss, A. P., Deckersbach, T., Goff, D. C., Morecraft, R. J., \& Bush, G. (2004). Anterior cingulate cortex activation during cognitive interference in schizophrenia. The American Journal of Psychiatry, 161, 707-715.

Hester, R. L., Murphy, K., Foxe, J. J., Foxe, D. M., Javitt, D. C., \& Garavan, H. (2004). Predicting success: Patterns of cortical activation and deactivation prior to response inhibition. Journal of Cognitive Neuroscience, 16, 776-785. doi:10.1162/ 089892904970726

Honey, G. D., Sharma, T. S., Suckling, J., Giampietro, V., Williams, S. C. R., \& Bullmore, E. T. (2003). The functional neuroanatomy of schizophrenic subsyndromes. Psychological Medicine, 33, 10071018.

Horn, N. R., Dolan, M., Elliott, R., Deakin, J. F. W., \& Woodruff, P. W. R. (2003). Response inhibition and impulsivity: An fMRI study. Neuropsychologia, 41, 1959-1966.

Hugdahl, K., Rund, B. R., Lund, A., Asbjornsen, A., Egeland, J., Ersland, L., . . . Thomsen, T. (2004). Brain activation measured with fMRI during a mental arithmetic task in schizophrenia and major depression. American Journal of Psychiatry, 161, 286-293.

Ischebeck, A., Zamarian, L., Siedentopf, C., Koppelstätter, F., Benke, T., Felber, S., \& Delazer, M. (2006). How specifically do we learn? Imaging the learning of multiplication and subtraction. NeuroImage, 30, 1365-1375. doi:10.1016/j. neuroimage.2005.11.016

Jacobsen, C. F. (1936). Studies of cerebral function in primates: I. The functions of the frontal association areas in monkeys. Comparative Psychology Monographs, 13, 1-60.

Johnson, M. R., Morris, N. A., Astur, R. S., Calhoun, V. D., Mathalon, D. H., Kiehl, K. A., \& Pearlson, G. D. (2006). A functional magnetic resonance imaging study of working memory abnormalities in schizophrenia. Biological Psychiatry, 60, 11-21. doi:10.1016/j.biopsych.2005.11.012

Jonides, J., Schumacher, E. H., Smith, E. E., Lauber, E. J., Awh, E., Minoshima, S., \& Koeppe, R. A. (1997). Verbal working memory load affects regional brain activation as measured by PET. Journal of Cognitive Neuroscience, 9, 462-475. doi:10.1162/jocn.1997.9.4.462
Kelly, A. M., Hester, R. L., Murphy, K., Javitt, D. C., Foxe, J. J., \& Garavan, H. (2004). Prefrontal-subcortical dissociations underlying inhibitory control revealed by event-related fMRI. European Journal of Neuroscience, 19, 3105-3112.

Kerns, J. G. (2006). Anterior cingulate and prefrontal cortex activity in an FMRI study of trial-to-trial adjustments on the Simon task. NeuroImage, 33, 399-405.

Kerns, J. G., Cohen, J. D., MacDonald, A. W., III, Johnson, M. K., Stenger, V. A., Aizenstein, H., \& Carter, C. S. (2005). Decreased conflict- and error-related activity in the anterior cingulate cortex in subjects with schizophrenia. The American Journal of Psychiatry, 162, 1833-1839. doi:10.1176/appi.ajp.162.10.1833

Kim, J.-J., Kim, M. S., Lee, J. S., Lee, D. S., Lee, M. C., \& Kwon, J. S. (2002). Dissociation of working memory processing associated with native and second languages: PET investigation. NeuroImage, 15, 879-891.

Kim, J.-J., Kwon, J. S., Park, H. J., Youn, T., Kang, D. H., Kim, M. S., . . Lee, M. C. (2003). Functional disconnection between the prefrontal and parietal cortices during working memory processing in schizophrenia: A $\left[{ }^{15} \mathrm{O} \mathrm{H}_{2} \mathrm{O}\right.$ PET study. American Journal of Psychiatry, 160, 919-923. doi:10.1176/ appi.ajp.160.5.919

Kimberg, D. Y., Aguirre, G. K., \& D’Esposito, M. (2000). Modulation of task-related neural activity in task-switching: An fMRI study. Cognitive Brain Research, 10, 189-196.

Kimmig, H., Greenlee, M. W., Gondan, M., Schira, M., Kassubek, J., \& Mergner, T. (2001). Relationship between saccadic eye movements and cortical activity as measured by fMRI: Quantitative and qualitative aspects. Experimental Brain Research, 141, 184-194.

Kirschen, M. P., Chen, S. H. A., Schraedley-Desmond, P., \& Desmond, J. E. (2005). Load- and practice-dependent increases in cerebrocerebellar activation in verbal working memory: An fMRI study. NeuroImage, 24, 462-472.

Klein, D., Milner, B., Zatorre, R. J., Meyer, E., \& Evans, A. C. (1995). The neural substrates underlying word generation: A bilingual functional-imaging study. Proceedings of the National Academy of Sciences, 92, 2899-2903.

Klein, D., Milner, B., Zatorre, R. J., Zhao, V., \& Nikelski, J. (1999). Cerebral organization in bilinguals: A PET study of ChineseEnglish verb generation. NeuroReport, 10, 2841-2846.

Konishi, S., Nakajima, K., Uchida, I., Kameyama, M., Nakahara, K., Sekihara, K., \& Miyashita, Y. (1998a). Transient activation of inferior prefrontal cortex during cognitive set shifting. Nature Neuroscience, 1, 80-84.

Konishi, S., Nakajima, K., Uchida, I., Kikyo, H., Kameyama, M., \& Miyashita, Y. (1999). Common inhibitory mechanism in human inferior prefrontal cortex revealed by event-related functional MRI. Brain, 122, 981-991.

Konishi, S., Nakajima, K., Uchida, I., Sekihara, K., \& Miyashita, Y. (1998b). No-go dominant brain activity in human inferior prefrontal cortex revealed by functional magnetic resonance imaging. European Journal of Neuroscience, 10, 1209-1213.

Kronhaus, D. M., Lawrence, N. S., Williams, A. M., Frangou, S., Brammer, M. J., Williams, S. C., . . . Phillips, M. L. (2006). Stroop performance in bipolar disorder: Further evidence for abnormalities in the ventral prefrontal cortex. Bipolar Disorders, 8, 28-39. doi:10.1111/j.1399-5618.2006.00282.x

Kumari, V., Aasen, I., Taylor, P., Ffytche, D. H., Das, M., Barkataki, I., . . Sharma, T. (2006). Neural dysfunction and violence in schizophrenia: An fMRI investigation. Schizophrenia Research, 84, 144-164. doi:10.1016/j.schres.2006.02.017

LaBar, K. S., Gitelman, D. R., Parrish, T. B., \& Mesulam, M. M. (1999). Neuroanatomic overlap of working memory and spatial attention networks: A functional MRI comparison within subjects. NeuroImage, 10, 695-704. 
Lagopoulos, J., Ivanovski, B., \& Malhi, G. S. (2007). An eventrelated functional MRI study of working memory in euthymic bipolar disorder. Journal of Psychiatry \& Neuroscience, 32, $174-184$.

Laird, A. R., Eickhoff, S. B., Kurth, F., Fox, P. M., Uecker, A. M., Turner, J. A., . . Fox, P. T. (2009). ALE meta-analysis workflows via the BrainMap database: Progress towards a probabilistic functional brain atlas. Frontiers in Neuroinformatics, 3, 23. doi:10.3389/ neuro.11.023.2009

Laird, A. R., Fox, P. M., Price, C. J., Glahn, D. C., Uecker, A. M., Lancaster, J. L., . . . Fox, P. T. (2005). ALE meta-analysis: Controlling the false discovery rate and performing statistical contrasts. Human Brain Mapping, 25, 155-164.

Laird, A. R., McMillan, K. M., Lancaster, J. L., Kochunov, P., Turkeltaub, P. E., Pardo, J. V., \& Fox, P. T. (2005b). A comparison of label-based review and ALE meta-analysis in the Stroop task. Human Brain Mapping, 25, 6-21. doi:10.1002/hbm.20129

Laird, A. R., Robinson, J. L., McMillan, K. M., Tordesillas-Gutiérrez, D., Moran, S. T., Gonzales, S. M., . . . Lancaster, J. L. (2010). Comparison of the disparity between Talairach and MNI coordinates in functional neuroimaging data: Validation of the Lancaster transform. NeuroImage, 51, 677-683. doi:10.1016/j. neuroimage.2010.02.048

Lancaster, J. L., Tordesillas-Gutiérrez, D., Martinez, M., Salinas, F., Evans, A., Zilles, K., . . . Fox, P. T. (2007). Bias between MNI and Talairach coordinates analyzed using the ICBM-152 brain template. Human Brain Mapping, 28, 1194-1205. doi:10.1002/ hbm. 20345

Landau, S. M., Schumacher, E. H., Garavan, H., Druzgal, T. J., \& D'Esposito, M. (2004). A functional MRI study of the influence of practice on component processes of working memory. NeuroImage, 22, 211-221.

Lange, G., Steffener, J., Cook, D. B., Bly, B. M., Christodoulou, C., Liu, W. C., . . Natelson, B. H. (2005). Objective evidence of cognitive complaints in Chronic Fatigue Syndrome: A BOLD fMRI study of verbal working memory. NeuroImage, 26, 513524. doi:10.1016/j.neuroimage.2005.02.011

Laurens, K. R., Kiehl, K. A., Ngan, E. T. C., \& Liddle, P. F. (2005). Attention orienting dysfunction during salient novel stimulus processing in schizophrenia. Schizophrenia Research, 75, 159171.

Lazeron, R. H. C., Rombouts, S. A. R. B., de Sonneville, L., Barkhof, F., \& Scheltens, P. (2003). A paced visual serial addition test for fMRI. Journal of the Neurological Sciences, 213, 29-34.

Lee, T. W., Dolan, R. J., \& Critchley, H. D. (2008). Controlling emotional expression: Behavioral and neural correlates of nonimitative emotional responses. Cerebral Cortex, 18, 104-113. doi:10.1093/cercor/bhm035

Leimkuhler, M. E., \& Mesulam, M. M. (1985). Reversible go-no go deficits in a case of frontal lobe tumor. Annals of Neurology, 18, $617-619$.

Leung, H. C., Gore, J. C., \& Goldman-Rakic, P. S. (2002). Sustained mnemonic response in the human middle frontal gyrus during online storage of spatial memoranda. Journal of Cognitive Neuroscience, 14, 659-671.

Leung, H. C., Skudlarski, P., Gatenby, J. C., Peterson, B. S., \& Gore, J. C. (2000). An event-related functional MRI study of the Stroop color word interference task. Cerebral Cortex, 10, $552-560$.

Lezak, M. (1995). Neuropsychological Assessment (3rd ed.). New York, NY: Oxford University Press.

Li, H., Chan, R. C., McAlonan, G. M., \& Gong, Q. Y. (2010). Facial emotion processing in schizophrenia: A meta-analysis of functional neuroimaging data. Schizophrenia Bulletin, 36, 1029-1039. doi:10.1093/schbul/sbn190
Liddle, P. F., Kiehl, K. A., \& Smith, A. M. (2001). Event-related fMRI study of response inhibition. Human Brain Mapping, 12, 100 109.

Linden, D. E. J., Bittner, R. A., Muckli, L., Waltz, J. A., Kriegeskorte, N., Goebel, R., . . . Munk, M. H. J. (2003). Cortical capacity constraints for visual working memory: Dissociation of fMRI load effects in a fronto-parietal network. NeuroImage, 20, 1518-1530. doi:10.1016/j.neuroimage.2003.07.021

Liu, X., Banich, M. T., Jacobson, B. L., \& Tanabe, J. L. (2004). Common and distinct neural substrates of attentional control in an integrated Simon and spatial Stroop task as assessed by eventrelated fMRI. NeuroImage, 22, 1097-1106. doi:10.1016/j. neuroimage.2004.02.033

Luks, T. L., Simpson, G. V., Feiwell, R. J., \& Miller, W. L. (2002). Evidence for anterior cingulate cortex involvement in monitoring preparatory attentional set. NeuroImage, 17, 792-802.

Luna, B., Padmanabhan, A., \& O'Hearn, K. (2010). What has fMRI told us about the development of cognitive control through adolescence? Brain and Cognition, 72, 101-113.

Luria, A. R. (1970). The functional organization of the brain. Scientific American, 222, 66-72. passim.

MacDonald, A. W., III, Carter, C. S., Kerns, J. G., Ursu, S., Barch, D. M., Holmes, A. J., . . . Cohen, J. D. (2005). Specificity of prefrontal dysfunction and context processing deficits to schizophrenia in never-medicated patients with first-episode psychosis. American Journal of Psychiatry, 162, 475-484. doi:10.1176/appi. ajp.162.3.475

MacDonald, A. W., III, \& Carter, C. S. (2003). Event-related FMRI study of context processing in dorsolateral prefrontal cortex of patients with schizophrenia. Journal of Abnormal Psychology, 112, 689-697.

MacDonald, A. W., III, Cohen, J. D., Stenger, V. A., \& Carter, C. S. (2000). Dissociating the role of the dorsolateral prefrontal and anterior cingulate cortex in cognitive control. Science, 288, 18351838.

Maclin, E. L., Gratton, G., \& Fabiani, M. (2001). Visual spatial localization conflict: An fMRI study. NeuroReport, 12, 36333636.

Maguire, R. P., Broerse, A., de Jong, B. M., Cornelissen, F. W., Meiners, L. C., Leenders, K. L., \& den Boer, J. A. (2003). Evidence of enhancement of spatial attention during inhibition of a visuo-motor response. NeuroImage, 20, 1339-1345. doi:10.1016/S1053-8119(03)00402-6

Maltby, N., Tolin, D. F., Worhunsky, P., O’Keefe, T. M., \& Kiehl, K. A. (2005). Dysfunctional action monitoring hyperactivates frontalstriatal circuits in obsessive-compulsive disorder: An eventrelated fMRI study. NeuroImage, 24, 495-503.

Mana, S., Paillere Martinot, M. L., \& Martinot, J. L. (2010). Brain imaging findings in children and adolescents with mental disorders: A cross-sectional review. European Psychiatry, $25,345-354$

Manoach, D. S., Gollub, R. L., Benson, E. S., Searl, M. M., Goff, D. C., Halpern, E., . . . Rauch, S. L. (2000). Schizophrenic subjects show aberrant fMRI activation of dorsolateral prefrontal cortex and basal ganglia during working memory performance. Biological Psychiatry, 48, 99-109.

Martinkauppi, S., Rama, P., Aronen, H. J., Korvenoja, A., \& Carlson, S. (2000). Working memory of auditory localization. Cerebral Cortex, 10, 889-898.

Matsuda, T., Matsuura, M., Ohkubo, T., Ohkubo, H., Matsushima, E., Inoue, K., . . . Kojima, T. (2004). Functional MRI mapping of brain activation during visually guided saccades and antisaccades: Cortical and subcortical networks. Psychiatry Research, 131, 147-155. doi:10.1016/j.pscychresns.2003.12.007

Matsuo, K., Glahn, D. C., Peluso, M. A. M., Hatch, J. P., Monkul, E. S., Najt, P., . . Soares, J. C. (2007). Prefrontal hyperactivation 
during working memory task in untreated individuals with major depressive disorder. Molecular Psychiatry, 12, 158-166. doi:10.1038/sj.mp.4001894

Mayer, J. S., Bittner, R. A., Nikolic, D., Bledowski, C., Goebel, R., \& Linden, D. E. J. (2007). Common neural substrates for visual working memory and attention. NeuroImage, 36, 441-453.

Mead, L. A., Mayer, A. R., Bobholz, J. A., Woodley, S. J., Cunningham, J. M., Hammeke, T. A., \& Rao, S. M. (2002). Neural basis of the Stroop interference task: Response competition or selective attention? Journal of the International Neuropsychological Society, 8, $735-742$.

Mendrek, A., Kiehl, K. A., Smith, A. M., Irwin, D., Forster, B. B., \& Liddle, P. F. (2005). Dysfunction of a distributed neural circuitry in schizophrenia patients during a working-memory performance. Psychological Medicine, 35, 187-196.

Menon, V. (2011). Large-scale brain networks and psychopathology: A unifying triple network model. Trends in Cognitive Sciences, 15, 483-506. doi:10.1016/j.tics.2011.08.003

Menon, V., Adelman, N. E., White, C. D., Glover, G. H., \& Reiss, A. L. (2001a). Error-related brain activation during a Go/NoGo response inhibition task. Human Brain Mapping, 12, 131-143.

Menon, V., Anagnoson, R. T., Mathalon, D. H., Glover, G. H., \& Pfefferbaum, A. (2001b). Functional neuroanatomy of auditory working memory in schizophrenia: Relation to positive and negative symptoms. NeuroImage, 13, 433-446.

Milham, M. P., \& Banich, M. T. (2005). Anterior cingulate cortex: An fMRI analysis of conflict specificity and functional differentiation. Human Brain Mapping, 25, 328-335.

Milham, M. P., Banich, M. T., Webb, A., Barad, V., Cohen, N. J., Wszalek, T., . . Kramer, A. F. (2001). The relative involvement of anterior cingulate and prefrontal cortex in attentional control depends on nature of conflict. Cognitive Brain Research, 12, 467473.

Milham, M. P., Erickson, K. I., Banich, M. T., Kramer, A. F., Webb, A., Wszalek, T. M., ... Cohen, N. J. (2002). Attentional control in the aging brain: Insights from an fMRI study of the Stroop task. Brain and Cognition, 49, 277-296. doi:10.1006/brcg.2001.1501

Miller, E. K. (2000). The prefrontal cortex and cognitive control. Nature Reviews Neuroscience, 1, 59-65.

Miller, E. K., \& Cohen, J. D. (2001). An integrative theory of prefrontal cortex function. Annual Review of Neuroscience, $24,167-202$.

Milner, B. (1982). Some cognitive effects of frontal-lobe lesions in man. Philosophical Transactions of the Royal Society B, 298, 211-226.

Minzenberg, M. J., Laird, A. R., Thelen, S., Carter, C. S., \& Glahn, D. C. (2009). Meta-analysis of 41 functional neuroimaging studies of executive function in schizophrenia. Archives of General Psychiatry, 66, 811-822.

Miyake, A., \& Shah, P. (1999). Models of working memory: Mechanisms of active maintenance and executive control. New York, NY: Cambridge University Press.

Molenberghs, P., Cunnington, R., \& Mattingley, J. B. (2009). Is the mirror neuron system involved in imitation? A short review and meta-analysis. Neuroscience and Biobehavioral Reviews, 33, 975-980.

Monchi, O., Petrides, M., Petre, V., Worsley, K. J., \& Dagher, A. (2001). Wisconsin Card Sorting revisited: Distinct neural circuits participating in different stages of the task identified by eventrelated functional magnetic resonance imaging. Journal of $\mathrm{Neu}$ roscience, $21,7733-7741$.

Monks, P. J., Thompson, J. M., Bullmore, E. T., Suckling, J., Brammer, M. J., Williams, S. C. R., . . Curtis, V. A. (2004). A functional MRI study of working memory task in euthymic bipolar disorder: Evidence for task-specific dysfunction. Bipolar Disorders, 6, 550-564. doi:10.1111/j.1399-5618.2004.00147.x
Mostofsky, S. H., Schafer, J. G. B., Abrams, M. T., Goldberg, M. C., Flower, A. A., Boyce, A., . . Pekar, J. J. (2003). fMRI evidence that the neural basis of response inhibition is task-dependent. Cognitive Brain Research, 17, 419-430.

Nagahama, Y., Fukuyama, H., Yamauchi, H., Katsumi, Y., Magata, Y., Shibasaki, H., \& Kimura, J. (1997). Age-related changes in cerebral blood flow activation during a Card Sorting Test. Experimental Brain Research, 114, 571-577.

Nagahama, Y., Fukuyama, H., Yamauchi, H., Matsuzaki, S., Konishi, J., Shibasaki, H., \& Kimura, J. (1996). Cerebral activation during performance of a card sorting test. Brain, 119, 1667-1675.

Nagahama, Y., Okada, T., Katsumi, Y., Hayashi, T., Yamauchi, H., Oyanagi, C., ... Shibasaki, H. (2001). Dissociable mechanisms of attentional control within the human prefrontal cortex. Cerebral Cortex, 11, 85-92. doi:10.1093/cercor/11.1.85

Norris, D. G., Zysset, S., Mildner, T., \& Wiggins, C. J. (2002). An investigation of the value of spin-echo-based fMRI using a Stroop color-word matching task and EPI at 3T. NeuroImage, 15, 719726.

O’Driscoll, G. A., Alpert, N. M., Matthysse, S. W., Levy, D. L., Rauch, S. L., \& Holzman, P. S. (1995). Functional neuroanatomy of antisaccade eye movements investigated with positron emission tomography. Proceedings of the National Academy of Sciences, 92, 925-929.

Owen, A. M., Downes, J. J., Sahakian, B. J., Polkey, C. E., \& Robbins, T. W. (1990). Planning and spatial working memory following frontal lobe lesions in man. Neuropsychologia, 28, 1021-1034.

Owen, A. M., Herrod, N. J., Menon, D. K., Clark, J. C., Downey, S. P. M. J., Carpenter, T. A., . . Pickard, J. D. (1999). Redefining the functional organization of working memory processes within human lateral prefrontal cortex. European Journal of Neuroscience, $11,567-574$

Owen, A. M., McMillan, K. M., Laird, A. R., \& Bullmore, E. (2005). $\mathrm{N}$-back working memory paradigm: A meta-analysis of normative functional neuroimaging studies. Human Brain Mapping, 25, 4659. doi:10.1002/hbm.20131

Owen, A. M., Stern, C. E., Look, R. B., Tracey, I., Rosen, B. R., \& Petrides, M. (1998). Functional organization of spatial and nonspatial working memory processing within the human lateral frontal cortex. Proceedings of the National Academy of Sciences, 95, 7721-7726.

Paus, T., Petrides, M., Evans, A. C., \& Meyer, E. (1993). Role of the human anterior cingulate cortex in the control of oculomotor, manual, and speech responses: A positron emission tomography study. Journal of Neurophysiology, 70, 453-469.

Pennington, B. F., \& Ozonoff, S. (1996). Executive functions and developmental psychopathology. Journal of Child Psychology and Psychiatry, 37, 51-87.

Perlstein, W. M., Dixit, N. K., Carter, C. S., Noll, D. C., \& Cohen, J. D. (2003). Prefrontal cortex dysfunction mediates deficits in working memory and prepotent responding in schizophrenia. Biological Psychiatry, 53, 25-38.

Petersen, S. E., Fox, P. T., Posner, M. I., Mintun, M. A., \& Raichle, M. E. (1988). Positron emission tomographic studies of the cortical anatomy of single-word processing. Nature, 331, 585-589.

Petersen, S. E., Fox, P. T., Posner, M. I., Mintun, M. A., \& Raichle, M. E. (1989). Positron emission tomographic studies of the processing of single words. Journal of Cognitive Neuroscience, 1, 153-170.

Peterson, B. S., Kane, M. J., Alexander, G. M., Lacadie, C., Skudlarski, P., Leung, H.-C., . . . Gore, J. C. (2002). An event-related functional MRI study comparing interference effects in the Simon and Stroop tasks. Cognitive Brain Research, 13, 427-440. doi:10.1016/S09266410(02)00054-X 
Petit, L., Courtney, S. M., Ungerleider, L. G., \& Haxby, J. V. (1998). Sustained activity in the medial wall during working memory delays. Journal of Neuroscience, 18, 9429-9437.

Petrides, M., Alivisatos, B., Meyer, E., \& Evans, A. C. (1993). Functional activation of the human frontal cortex during the performance of verbal working memory tasks. Proceedings of the National Academy of Sciences, 90, 878-882.

Pochon, J.-B., Levy, R., Poline, J.-B., Crozier, S., Lehéricy, S., Pillon, B., . . . Dubois, B. (2001). The role of dorsolateral prefrontal cortex in the preparation of forthcoming actions: An fMRI study. Cerebral Cortex, 11, 260-266. doi:10.1093/cercor/11.3.260

Posner, M. I., \& Petersen, S. E. (1990). The attention system of the human brain. Annual Review of Neuroscience, 13, 25-42.

Ragland, J. D., Laird, A. R., Ranganath, C., Blumenfeld, R. S., Gonzales, S. M., \& Glahn, D. C. (2009). Prefrontal activation deficits during episodic memory in schizophrenia. The American Journal of Psychiatry, 166, 863-874. doi:10.1176/ appi.ajp.2009.08091307

Ragland, J. D., Turetsky, B. I., Gur, R. C., Gunning-Dixon, F., Turner, T., Schroeder, L., . . . Gur, R. E. (2002). Working memory for complex figures: An fMRI comparison of letter and fractal $n$-back tasks. Neuropsychology, 16, 370-379.

Rao, S. M., Bobholz, J. A., Hammeke, T. A., Rosen, A. C., Woodley, S. J., Cunningham, J. M., . . . Binder, J. R. (1997). Functional MRI evidence for subcortical participation in conceptual reasoning skills. NeuroReport, 8, 1987-1993.

Ravizza, S. M., \& Carter, C. S. (2008). Shifting set about task switching: Behavioral and neural evidence for distinct forms of cognitive flexibility. Neuropsychologia, 46, 2924-2935. doi:10.1016/j. neuropsychologia.2008.06.006

Richlan, F., Kronbichler, M., \& Wimmer, H. (2009). Functional abnormalities in the dyslexic brain: A quantitative meta-analysis of neuroimaging studies. Human Brain Mapping, 30, 3299-3308.

Rogers, R. D., Andrews, T. C., Grasby, P. M., Brooks, D. J., \& Robbins, T. W. (2000). Contrasting cortical and subcortical activations produced by attentional-set shifting and reversal learning in humans. Journal of Cognitive Neuroscience, 12, 142-162.

Roth, R. M., Koven, N. S., Randolph, J. J., Flashman, L. A., Pixley, H. S., Ricketts, S. M., . . S Saykin, A. J. (2006). Functional magnetic resonance imaging of executive control in bipolar disorder. NeuroReport, 17, 1085-1089. doi:10.1097/01.wnr.0000227979.06013.57

Roth, R. M., Saykin, A. J., Flashman, L. A., Pixley, H. S., West, J. D., \& Mamourian, A. C. (2007). Event-related functional magnetic resonance imaging of response inhibition in obsessivecompulsive disorder. Biological Psychiatry, 62, 901-909.

Rowe, J. B., Toni, I., Josephs, O., Frackowiak, R. S. J., \& Passingham, R. E. (2000). The prefrontal cortex: Response selection or maintenance within working memory? Science, 288, 1656-1660.

Rubia, K., Russell, T., Overmeyer, S., Brammer, M. J., Bullmore, E. T., Sharma, T., . . Taylor, E. (2001). Mapping motor inhibition: Conjunctive brain activations across different versions of go/ no-go and stop tasks. NeuroImage, 13, 250-261. doi:10.1006/ nimg. 2000.0685

Rubia, K., Smith, A. B., Woolley, J., Nosarti, C., Heyman, I., Taylor, E., \& Brammer, M. (2006). Progressive increase of frontostriatal brain activation from childhood to adulthood during event-related tasks of cognitive control. Human Brain Mapping, 27, 973-993. doi: $10.1002 / \mathrm{hbm} .20237$

Ruff, C. C., Woodward, T. S., Laurens, K. R., \& Liddle, P. F. (2001). The role of the anterior cingulate cortex in conflict processing: Evidence from reverse Stroop interference. NeuroImage, 14, $1150-1158$

Rushworth, M. F., Hadland, K. A., Paus, T., \& Sipila, P. K. (2002). Role of the human medial frontal cortex in task switching: A combined fMRI and TMS study. Journal of Neurophysiology, 87, 2577-2592.
Rypma, B., Prabhakaran, V., Desmond, J. E., \& Gabrieli, J. D. E. (2001). Age differences in prefrontal cortical activity in working memory. Psychology and Aging, 16, 371-384.

Rypma, B., Prabhakaran, V., Desmond, J. E., Glover, G. H., \& Gabrieli, J. D. E. (1999). Load-dependent roles of frontal brain regions in the maintenance of working memory. NeuroImage, 9, 216-226.

Samson, F., Mottron, L., Soulieres, I., \& Zeffiro, T. A. (2011). Enhanced visual functioning in autism: An ALE metaanalysis. Human Brain Mapping.

Sánchez-Cárrion, R., Gómez, P. V., Junqué, C., Fernández-Espejo, D., Falcon, C., Bargalló, N., . . . Bernabeu, M. (2008). Frontal hypoactivation on functional magnetic resonance imaging in working memory after severe diffuse traumatic brain injury. Journal of Neurotrauma, 25, 479-494. doi:10.1089/neu.2007.0417

Schumacher, E. H., Lauber, E. J., Awh, E., Jonides, J., Smith, E. E., \& Koeppe, R. A. (1996). PET evidence for an amodal verbal working memory system. NeuroImage, 3, 79-88.

Schwindt, G. C., \& Black, S. E. (2009). Functional imaging studies of episodic memory in Alzheimer's disease: A quantitative metaanalysis. NeuroImage, 45, 181-190.

Shallice, T. (1982). Specific impairments of planning. Philosophical Transactions of the Royal Society B, 298, 199-209.

Shallice, T. (1988). From neuropsychology to mental structure. New York, NY: Cambridge University Press.

Sheridan, M. A., Hinshaw, S., \& D'Esposito, M. (2007). Efficiency of the prefrontal cortex during working memory in attention-deficit/ hyperactivity disorder. Journal of the American Academy of Child and Adolescent Psychiatry, 46, 1357-1366. doi:10.1097/ chi.0b013e31812eecf7

Smith, E. E., \& Jonides, J. (1999). Storage and executive processes in the frontal lobes. Science, 283, 1657-1661. doi:10.1126/ science.283.5408.1657

Smith, E. E., Jonides, J., \& Koeppe, R. A. (1996). Dissociating verbal and spatial working memory using PET. Cerebral Cortex, 6, 11-20.

Smith, A. B., Taylor, E., Brammer, M. J., \& Rubia, K. (2004). Neural correlates of switching set as measured in fast, event-related functional magnetic resonance imaging. Human Brain Mapping, $21,247-256$.

Sohn, M. H., Ursu, S., Anderson, J. R., Stenger, V. A., \& Carter, C. S. (2000). The role of prefrontal cortex and posterior parietal cortex in task switching. Proceedings of the National Academy of Sciences, 97, 13448-13453.

Sommer, M., Hajak, G., Döhnel, K., Meinhardt, J., \& Müller, J. L. (2008). Emotion-dependent modulation of interference processes: An fMRI study. Acta Neurobiologiae Experimentalis, 68, 193-203.

Spaniol, J., Davidson, P. S., Kim, A. S., Han, H., Moscovitch, M., \& Grady, C. L. (2009). Event-related fMRI studies of episodic encoding and retrieval: Meta-analyses using activation likelihood estimation. Neuropsychologia, 47, 1765-1779.

Spreng, R. N., Stevens, W. D., Chamberlain, J. P., Gilmore, A. W., \& Schacter, D. L. (2010). Default network activity, coupled with the frontoparietal control network, supports goal-directed cognition. NeuroImage, 53, 303-317.

Stark, C. E., \& Squire, L. R. (2001). When zero is not zero: The problem of ambiguous baseline conditions in fMRI. Proceedings of the National Academy of Sciences, 98, 12760-12766.

Stern, C. E., Owen, A. M., Tracey, I., Look, R. B., Rosen, B. R., \& Petrides, M. (2000). Activity in ventrolateral and mid-dorsolateral prefrontal cortex during nonspatial visual working memory processing: Evidence from functional magnetic resonance imaging. NeuroImage, 11, 392-399.

Sweeney, J. A., Mintun, M. A., Kwee, S., Wiseman, M. B., Brown, D. L., Rosenberg, D. R., \& Carl, J. R. (1996). Positron emission tomography study of voluntary saccadic eye movements and spatial working memory. Journal of Neurophysiology, 75, 454468. 
Tang, J., Critchley, H. D., Glaser, D. E., Dolan, R. J., \& Butterworth, B. (2006). Imaging informational conflict: A functional magnetic resonance imaging study of numerical Stroop. Journal of Cognitive Neuroscience, 18, 2049-2062.

Taylor, S. F., Kornblum, S., Lauber, E. J., Minoshima, S., \& Koeppe, R. A. (1997). Isolation of specific interference processing in the Stroop task: PET activation studies. NeuroImage, 6, 81-92.

Turkeltaub, P. E., \& Coslett, H. B. (2010). Localization of sublexical speech perception components. Brain and Language, 114, 1-15. doi:10.1016/j.bandl.2010.03.008

Turkeltaub, P. E., Eden, G. F., Jones, K. M., \& Zeffiro, T. A. (2002). Meta-analysis of the functional neuroanatomy of single-word reading: Method and validation. NeuroImage, 16, 765-780.

Ullsperger, M., \& von Cramon, D. Y. (2001). Subprocesses of performance monitoring: A dissociation of error processing and response competition revealed by event-related fMRI and ERPs. NeuroImage, 14, 1387-1401.

van den Heuvel, O. A., Veltman, D. J., Groenewegen, H. J., Cath, D. C., van Balkom, A. J. L. M., van Hartskamp, J., . . van Dyck, R. (2005). Frontal-striatal dysfunction during planning in obsessivecompulsive disorder. Archives of General Psychiatry, 62, 301309. doi:10.1001/archpsyc.62.3.301

van der Wee, N. J. A., Ramsey, N. F., Jansma, J. M., Denys, D. A., van Megen, H. J. G. M., Westenberg, H. M. G., \& Kahn, R. S. (2003). Spatial working memory deficits in obsessive compulsive disorder are associated with excessive engagement of the medial frontal cortex. NeuroImage, 20, 2271-2280.

van Veen, V., Cohen, J. D., Botvinick, M. M., Stenger, V. A., \& Carter, C. S. (2001). Anterior cingulate cortex, conflict monitoring, and levels of processing. NeuroImage, 14, 1302-1308.

Veltman, D. J., Rombouts, S. A. R. B., \& Dolan, R. J. (2003). Maintenance versus manipulation in verbal working memory revisited: An fMRI study. NeuroImage, 18, 247-256.

Vincent, J. L., Kahn, I., Snyder, A. Z., Raichle, M. E., \& Buckner, R. L. (2008). Evidence for a frontoparietal control system revealed by intrinsic functional connectivity. Journal of Neurophysiology, 100, 3328-3342.

Vink, M., Kahn, R. S., Raemaekers, M., van den Heuvel, M., Boersma, M., \& Ramsey, N. F. (2005). Function of striatum beyond inhibition and execution of motor responses. Human Brain Mapping, $25,336-344$

Volle, E., Pochon, J. B., Lehericy, S., Pillon, B., Dubois, B., \& Levy, R. (2005). Specific cerebral networks for maintenance and response organization within working memory as evidenced by the "double delay/double response" paradigm. Cerebral Cortex, 15, 1064-1074.

Walter, H., Wolf, R. C., Spitzer, M., \& Vasic, N. (2007). Increased left prefrontal activation in patients with unipolar depression: An event-related, parametric, performance-controlled fMRI study. Journal of Affective Disorders, 101, 175-185.

Watanabe, M. (1990). Prefrontal unit activity during associative learning in the monkey. Experimental Brain Research, 80, 296-309.
Watanabe, M. (1992). Frontal units of the monkey coding the associative significance of visual and auditory stimuli. Experimental Brain Research, 89, 233-247.

Watanabe, J., Sugiura, M., Sato, K., Sato, Y., Maeda, Y., Matsue, Y., . . . Kawashima, R. (2002). The human prefrontal and parietal association cortices are involved in NO-GO performances: An event-related fMRI study. NeuroImage, 17, 1207-1216. doi:10.1006/ nimg.2002.1198

Wittfoth, M., Buck, D., Fahle, M., \& Herrmann, M. (2006). Comparison of two Simon tasks: Neuronal correlates of conflict resolution based on coherent motion perception. NeuroImage, 32, 921-929.

Wittfoth, M., Kustermann, E., Fahle, M., \& Herrmann, M. (2008). The influence of response conflict on error processing: Evidence from event-related fMRI. Brain Research, 1194, 118-129.

Yarkoni, T., Barch, D. M., Gray, J. R., Conturo, T. E., \& Braver, T. S. (2009). BOLD correlates of trial-by-trial reaction time variability in gray and white matter: A multi-study fMRI analysis. PLoS One, 4, e4257.

Yarkoni, T., Gray, J. R., Chrastil, E. R., Barch, D. M., Green, L., \& Braver, T. S. (2005). Sustained neural activity associated with cognitive control during temporally extended decision making. Cognitive Brain Research, 23, 71-84.

Yoo, S. S., Choi, B. G., Juh, R. H., Park, J. M., Pae, C. U., Kim, J. J., . . Lee, C. U. (2005). Working memory processing of facial images in schizophrenia: fMRI investigation. International Journal of Neuroscience, 115, 351-366. doi:10.1080/00207450590520957

Yoon, J. H., Minzenberg, M. J., Ursu, S., Walter, R. B. S., Wendelken, C., Ragland, J. D., \& Carter, C. S. (2008). Association of dorsolateral prefrontal cortex dysfunction with disrupted coordinated brain activity in schizophrenia: Relationship with impaired cognition, behavioral disorganization, and global function. The American Journal of Psychiatry, 165, 1006-1014. doi:10.1176/appi. ajp.2008.07060945

Yu, K., Cheung, C., Leung, M., Li, Q., Chua, S., \& McAlonan, G. (2010). Are bipolar disorder and schizophrenia neuroanatomically distinct? An anatomical likelihood meta-analysis. Frontiers in Human Neuroscience, 4, 189.

Yücel, M., Harrison, B. J., Wood, S. J., Fornito, A., Wellard, R. M., Pujol, J., . . . Pantelis, C. (2007). Functional and biochemical alterations of the medial frontal cortex in obsessive-compulsive disorder. Archives of General Psychiatry, 64, 946-955. doi:10.1001/archpsyc.64.8.946

Zago, L., Pesenti, M., Mellet, E., Crivello, F., Mazoyer, B., \& TzourioMazoyer, N. (2001). Neural correlates of simple and complex mental calculation. NeuroImage, 13, 314-327.

Zurowski, B., Gostomzyk, J., Grön, G., Weller, R., Schirrmeister, H., Neumeier, B., . . . Walter, H. (2002). Dissociating a common working memory network from different neural substrates of phonological and spatial stimulus processing. NeuroImage, 15, 45-57.

Zysset, S., Muller, K., Lohmann, G., \& von Cramon, D. Y. (2001). Color-word matching Stroop task: Separating interference and response conflict. NeuroImage, 13, 29-36. 